Alma Mater Studiorum - Università di Bologna DEPARTMENT OF ECONOMICS

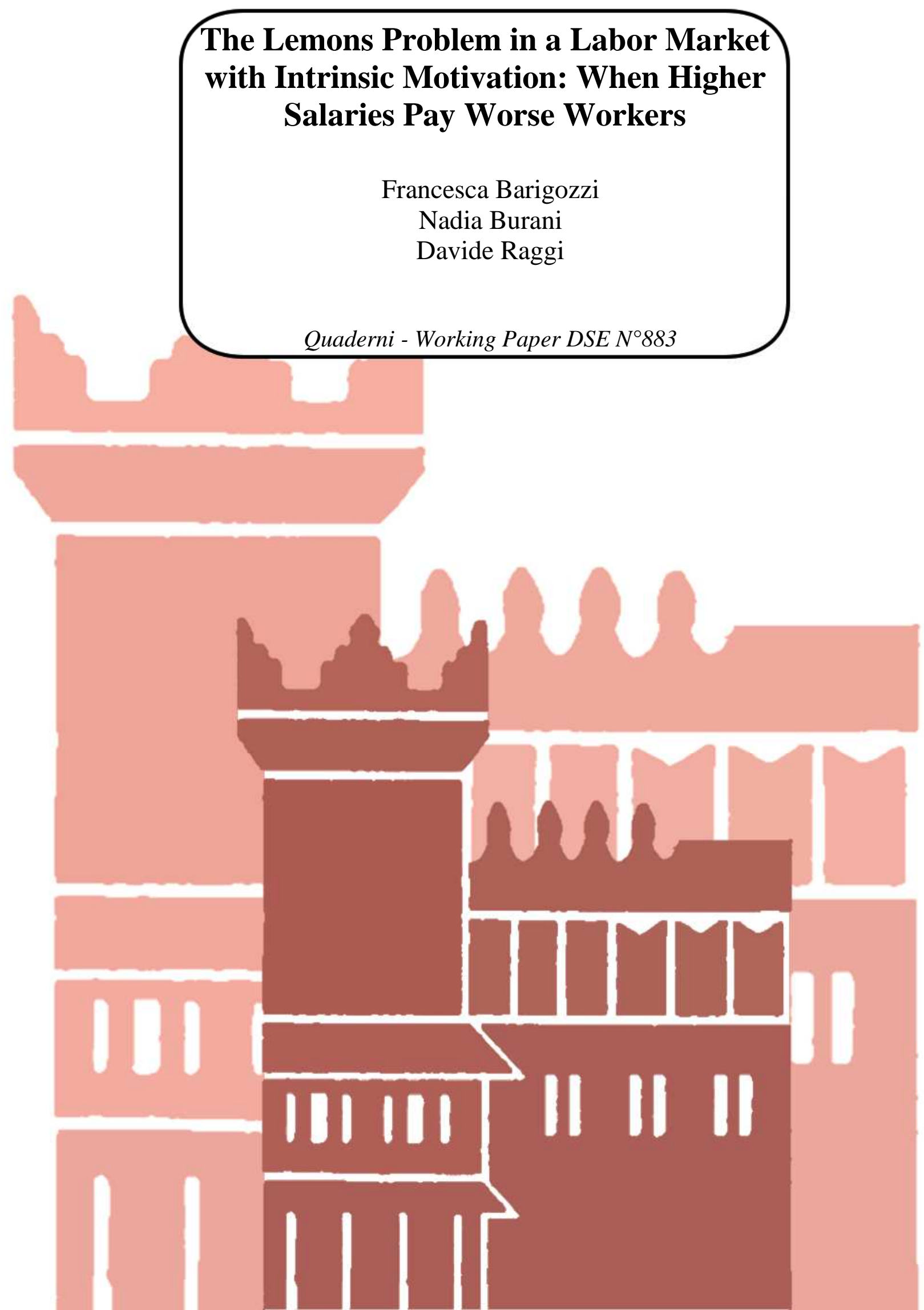




\title{
The Lemons Problem in a Labor Market with Intrinsic Motivation: When Higher Salaries Pay Worse Workers*
}

\author{
Francesca Barigozzi $\dagger$ Nadia Burani ${ }^{\ddagger}$ and Davide Raggi ${ }^{\S}$ \\ University of Bologna
}

June 2014

\begin{abstract}
We study the Lemons Problem when workers have private information on both their skills and their intrinsic motivation. When workers are motivated, inefficiencies due to adverse selection are mitigated and a change in salaries may have unexpected consequences. With a sufficiently strong and positive association between motivation and productivity, a wage increase may attract less motivated and also less productive workers. When the association is positive but small, it instead may attract more productive and also more motivated workers. Our theoretical analysis reconciles contrasting empirical evidence on vocational sectors such as for public servants, teachers, health professionals and politicians. Our results also inform the current policy debate on whether it is possible to improve the overall quality of workers by changing their salary.
\end{abstract}

JEL Classification: J24, J21, J3, D82.

Key Words: skills, intrinsic motivation, the bidimensional Lemons Problem, labor supply.

*This work builds on a previous paper circulated under the title "Adverse selection in a vocation-based labor market". We are particularly grateful to Giacomo Calzolari. We also thank Leonardo Becchetti, Matteo Lippi Bruni, Robert Dur, Philippe Février, Andrea Ichino, Tor Iversen, Concetta Mendolicchio, Natalia Montinari, Thomas Philippon, Tommaso Reggiani and Paolo Vanin for helpful comments and suggestions. We are indebted to Giulio Ecchia and AICCON for providing the ICSE 2007dataset. We thank the audience at the European Health Economics Workshop, the EARIE conference in Istanbul, the Journées d'Economie Publique Louis-André Gérard-Varet and at the Market and Happiness conference at the University of Milan Bicocca. Finally we thank the participants at the seminars of the Universities of Bologna, Brescia, Catania, Padua Milan Statale and of Boston University.

${ }^{\dagger}$ Department of Economics, University of Bologna, P.zza Scaravilli 2, 40126 Bologna (Italy). E-mail address: francesca.barigozzi@unibo.it

${ }^{\ddagger}$ Department of Economics, University of Bologna, Strada Maggiore 45, 40126 Bologna (Italy). E-mail address: nadia.burani@unibo.it

$\S$ Department of Economics, University of Bologna, P.zza Scaravilli 2, 40126 Bologna (Italy). E-mail address: davide.raggi@unibo.it 


\section{Introduction}

The problem of the selection of the best possible applicants to a job opening has received considerable attention in the labor economics literature. It is usually acknowledged that higher wages are necessary to attract applicants with higher skills or ability. ${ }^{1}$ We show that this is not always true, when a vocational labor market is considered in which workers are heterogeneous in both their ability and their motivation for the task to be performed.

Our paper theoretically investigates the (self-)selection of applicants into a sector where both skills and workers' intrinsic motivation are private information to the workers. We show that changes in the composition of the pool of applicants due to changes in the offered wage rate dramatically depend on the distribution of ability and motivation in the population of potential workers. In particular, we will find that, because of the interplay between ability and motivation in the workers' participation constraint, it is possible that higher wages attract workers characterized by lower ability and lower motivation on average. A "Lemons problem" with bidimensional adverse selection thus arises.

When firms in a competitive market offer a job to workers who have private information on their productivity only, it is well known that inefficiencies arise (the "standard" Lemons problem). In particular, efficiency would require the firms to offer a different wage to workers characterized by different productivity levels. However, because of asymmetric information, firms offer a uniform wage to all the workers. When the workers' outside option is contingent on workers' ability, workers' decisions on accepting the job or not depend on their productivity level in a way that adversely affects the firms: outside the market the payoff is larger for more productive workers, thus only relatively less capable workers are willing to accept the job at any given uniform wage offered by firms. This leads to an inefficiently low employment rate, to a low average productivity of active workers and, what is more important to us, the average productivity of active workers is monotonically increasing in the wage rate.

Consider now a vocational market such that each worker also privately knows how much he/she is motivated for the job offered by firms. How does this second source of workers' private information affect the Lemons Problem? How is labor supply characterized in this vocational market? In particular, do higher salaries still attract more productive workers?

Intrinsic motivation is interpreted as a benefit accruing to workers' utility when employed in a vocational sector, unrelated to workers' effort or output (see also Heyes 2005, Delfgaauw and Dur 2010 and Dal Bò et al. 2013). A "vocational labor market" is thus a sector where motivated workers receive a "vocational premium", whereas a "standard labor market" is a sector offering no vocational premium.

We first analyze the natural framework of adverse selection in markets in which: $(i)$ the opportunity cost of accepting the job in the vocational-market is increasing in workers' productivity; and (ii) for

\footnotetext{
${ }^{1}$ In what follows, we will use the terms skills, ability and productivity interchangeably.
} 
informational or institutional reasons firms in the vocational sector can only offer a uniform wage, i.e. a salary that is independent of productivity and vocation. However, our model is general enough to also accommodate and describe different situations, for example where the wage rate rewards workers' productivity, i.e. firms in the vocational sector use incentive schemes. ${ }^{2}$

We compare the inefficiency caused by adverse selection in the Vocational Lemons Model with that in the Standard Lemons Model in which intrinsic motivation is irrelevant and does not affect workers' participation constraint. We show that a vocational market attracts high vocation workers characterized, also, by high productivity. Thus, intrinsic motivation mitigates the production inefficiency due to adverse selection.

We obtain a rich set of results concerning how average productivity and average vocation of active workers change with the wage rate and, as we discuss below, we are able to reconcile contrasting empirical evidence on the different vocational sectors. Intuitively, as the wage increases, more skilled workers become interested in the job; on the other hand, less motivated candidates apply for the job when there is a negative statistical association between productivity and vocation or when the two characteristics are independently distributed. This "intuitive case" indeed shows that, in order to attract more highly skilled applicants, higher wages may be necessary; but this comes at the cost of attracting less motivated workers (see, among others, also Delfgaauw and Dur 2010 and Dal Bò et al. 2013). However, we show that two "counter-intuitive" and mutually exclusive cases can also emerge in the case of a positive statistical association between productivity and vocation.

If the wage rate increases, then: either $(i)$ the average productivity of active workers can actually fall; or (ii) the average vocation can instead rise. A sufficient condition for result (i) concerning average productivity is the existence of at least a level of salary such that active workers have average productivity above the average of the entire population. Similarly, the condition for result (ii) on average motivation is the existence of at least a level of salary such that active workers have an average motivation below the average of the entire population.

To account for the mechanism driving the counter-intuitive results suppose that, for a given wage rate, a pool of workers enters the market having average productivity above the population average. Then, an increase in salary necessarily brings into the sector workers with below-average productivity, implying that the average productivity of active workers decreases for at least a subinterval of possible wage levels. Conversely, consider now a pool of workers with average vocation lower than the population. Then, an increase in salary brings into the market workers with above-average vocation, implying that the average vocation of active workers is going to increase.

Importantly, the sufficient condition for each one of the two counter-intuitive effects is consistent

\footnotetext{
${ }^{2}$ The alternative interpretations will be discussed in the paper, together with conditions such that results of the baseline model still hold.
} 
with a positive statistical association between productivity and vocation in the population of potential workers. This means that the two effects cannot coexist and that an increase in the wage either can make both average productivity and vocation of active workers jointly increase, or jointly decrease. In the first case, we observe that the pool of active workers improves with respect to both workers' characteristics, ${ }^{3}$ whereas in the second case we observe that the pool deteriorates.

Note that, in our model, workers' motivation has no direct impact on firms' output. However, it indirectly affects the sector's production by means of the self-selection mechanism of workers into the vocational market; such selection pattern, in turn, is driven by the joint distribution function of skills and motivation in the population of potential workers. In the end, the magnitude of the positive association between the two characteristics determines which counter-intuitive effect arises. Indeed, when the association between skills and motivation is strong, then motivation has a relatively higher impact on workers' participation constraint than ability. This in turn implies that average motivation of active workers decreases with the salary. However, because of the positive association between motivation and ability, average ability might decrease as well for a non-empty set of possible wage levels. So that, together with the fall in motivation, we may observe a fall in production. The opposite phenomenon occurs when the association between skills and motivation is still positive but weak. In this case, ability has a relatively higher impact on workers' participation constraint than motivation so that, as expected, average productivity of active workers increases with the salary. However, because of the positive association between the two characteristics, higher average ability goes hand by hand with higher average motivation. Then, an increase in the wage rate ultimately causes an increase in both production and motivation.

How to attract better applicants has been investigated, both theoretically and empirically, in specific vocational markets, such as the market for teachers ${ }^{4}$, the market for nurses ${ }^{5}$, for civil servants ${ }^{6}$ and for politicians ${ }^{7}$.

Some theoretical contributions focus on workers' motivation only (see Handy and Katz 1998, Francois 2000, Heyes 2005, Delfgaauw and Dur 2007, Prendergast 2007). They point out that motivated workers are characterized by lower reservation wages so that, by increasing the offered salary, firms also attract workers that are less motivated for the job and, as a result, the average level of motivation in the pool of active workers decreases. The effect of asymmetric information with respect to both productivity and

\footnotetext{
${ }^{3}$ This is precisely the case analyzed in Dal Bò et al. (2013) that will be discussed in more detail in what follows.

${ }^{4}$ Among others Figlio and Stone (1997), Figlio and Lucas (2000), Figlio (1997), Nickell and Quintini (2002), Dolton and Marcenaro-Gutierrez (2011).

${ }^{5}$ For example Heyes (2005) and Barigozzi and Turati (2012).

${ }^{6}$ Francois (2000), (2007), Prendergast (2007), Besley and Ghatak (2005), Delfgaauw and Dur (2008), (2010), Macchiavello (2008) and Dal Bò et al. (2013).

${ }^{7}$ Besley (2004), (2005), Caselli and Morelli (2004), Messner and Polborn (2004), Keane and Merlo (2010), Mattozzi and Merlo (2008), Ferraz and Finam (2011), Fisman et al. (2012).
} 
motivation has been analyzed by Dal Bò et al. (2013) in a theoretical model developed to guide their empirical inquiry. The authors restrict the distribution of the two characteristics in the population of potential workers by only considering two extreme cases: either ability and motivation are assumed to be independently distributed among the population or a positive and perfect correlation between the two variables exists (in practice, the workers' type space becomes unidimensional). They find conditions such that higher wages increase average motivation in the applicant pool. However, their model predicts that higher wages always increase average skills in the applicant pool, so that it is not able to explain some of the existing empirical evidence that we are going to discuss below.

The empirical evidence on the effect of a wage rate increase on the quality of the active work-force is controversial. Several papers focus on workers' skills, and document that higher wages increase applicants' skills, measured by different proxies. ${ }^{8}$ Important exceptions are Merlo et al. (2009) and Fisman et al. (2012) who find the opposite pattern in the case of politicians. The empirical question concerning motivation is more difficult to assess. Dal Bò et al. (2013) analyze how skills and intrinsic motivation of public servants are affected by a wage increase. Interestingly, the field experiment that they analyze shows that higher salaries attract workers who are more skilled and have a higher proclivity toward public sector.

Our model offers a theory of how the distribution of ability and motivation in the population of potential workers determines the impacts of a wage change on the composition of the work-force in vocational sectors. Despite its extreme simplicity, our model is sufficiently general to characterize in a unified framework different possible outcomes and to reconcile the contrasting evidence identified so far in the empirical literature, as we discuss in the following subsection. Our results also provide new insights into the ongoing debate on how to increase the supply and the quality of the work-force in vocational markets.

\subsection{Reconciling different empirical evidence}

Let us start with the market for politicians.

At the European level, Fisman et al. (2012) consider the introduction of a law that equalized the salaries of the members of the European parliament, starting from 2009. The authors show that doubling the salary of European politicians decreases the probability that an elected member of the parliament attended a college ranked among the top 500 in the world by 14 percent. Moreover, a salary increase seems to attract politicians who shirk more (but this effect, however, is not robust to inclusion of country fixed effects). Overall, their evidence suggests that higher salaries lower the quality of elected members of the European parliament. This evidence is consistent with the predictions of our theoretical model for

\footnotetext{
${ }^{8}$ See Gagliarducci and Nannicini (2013), Ferraz and Finam (2011) and Dolton and Marcenaro-Gutierrez (2011), among others.
} 
the counter-intuitive case $(i)$ arising when there exists a positive and strong association between skills and motivation in the population of potential workers: under these conditions, a higher wage attracts workers characterized by lower skills and lower motivation on average.

At the country level, Merlo et al. (2009) study the labor supply of politicians using data on the Italian parliament. They account that, between 1985 and 2004, the average real total annual income of Italian legislators grew at an average annual growth rate of 3.8\% making politics in Italy a highly lucrative occupation. Despite this sharp wage increase in the past twenty years, Merlo et al. (2009) show that today representatives are much less educated than in the past and have a lower outside opportunity. The authors thus document a negative correlation between what we can interpret as the skills of elected legislators and the parliamentary wage. Moreover, they study the degree of participation in parliamentary activity which, in our framework, could be interpreted as a proxy for the intrinsic motivation of elected officials. The authors find no evidence of a positive effect of the wage increase on the degree of participation. Again, these findings are consistent with the most striking outcome of our paper, i.e. that higher salaries can attract less skilled workers.

At the local level, evidence from Italy is different. Gagliarducci and Nannicini (2013) use data from Italian municipal governments from 1993 to 2001 showing that higher wages attract more educated and more efficient candidates. In the same line Ferraz and Finam (2011), examining Brazil's municipalities, showed that higher salaries attract candidates that are more educated and have more experience. Since the last two papers do not explicitly measure the politicians' motivation, their evidence is consistent with both the intuitive situation in which average productivity of active workers increases whereas average motivation decreases, and with the counter-intuitive case where both average motivation and average productivity of active workers increase.

Moving from politicians to teachers, let us report results from Dolton and Marcenaro-Gutierrez (2011), which are consistent with the same two above-mentioned scenarios. Studying the variation in teachers' pay across OECD countries and its significance for educational outcome, they find a clear statistical association between higher relative teachers' salaries and higher standardized pupil scores across countries. They conclude that better wages attract teachers with higher degrees and improve students' performance. As a consequence, they suggest increasing teacher salaries as a policy measure to help schools to recruit and retain the higher ability teachers.

Last, but not least, Dal Bò et al. (2013) study a recruitment drive for public sector positions in Mexico. In their field experiment both applicants' intellectual ability and motivation are accurately documented. Intellectual ability is directly measured by the applicants' IQ index and indirectly by their current earning in the market (the applicant's outside opportunity). Motivation is defined as the "inclination towards the public sector employment" and is measured using Perry's 1996 scale of Public Service Motivation. The authors show that higher wages attract applicants that are smarter (have a higher IQ index), have better 
personality traits, higher earnings and a better occupational profiles. Moreover, they find no evidence of adverse selection effects on motivation and, instead, document strong evidence of positive selection as for reciprocity, engagement in pro-social behaviors and willingness to cooperate. Results from this field experiment thus describe a case where higher wages attract workers that are better in terms of both ability and motivation. In terms of our theoretical model, this selection pattern would document the counter-intuitive case $(i i)$ that arises when ability and motivation have a positive but weak association in the population of applicants.

The rest of this paper is organized as follows. Section 2 describes the model set up and Subsection 2.1 illustrates two alternative specifications of the model. In Section 3 we study adverse selection in the Lemons model with intrinsic motivation. In Section 4 we analyze labor supply by investigating how average productivity and average motivation of active workers change with the wage rate. In Subsection 4.1 we study the case of a linear relationship between productivity and motivation. We discuss policy implications in Subsection 4.2. Section 5 concludes. In Appendix A.5 we provide simulations documenting the intuitive and counter-intuitive cases. In Appendix A.6 we show evidence of a positive dependence between productivity and vocation in data provided by the Italian survey ICSI 2007.

\section{A simple labor market model}

Consider a labor market consisting of two different sectors. In the "vocational sector" (for instance, the market for health professionals, teachers, civil servants or politicians) motivated workers obtain a vocational premium together with their salary. Alternatively, workers may decide to enter an "outsideoption sector" which is non-vocational, where workers only receive a monetary compensation.

In both sectors firms produce output using a technology in which labor is the only input. Since we are interested in the supply side of the vocational market, we do not extensively model firms' behavior.

The risk-neutral potential workers are heterogeneous with respect to both their productivity and their intrinsic motivation. Workers' productivity is denoted by $\theta$ and is interpreted as the number of units of output workers produce if hired in the vocational sector, with $\theta \in[\underline{\theta}, \bar{\theta}]$, and $0<\underline{\theta}<\bar{\theta}$. As for vocation or intrinsic motivation, several ways of modelling it have been proposed in the literature. We follow Heyes (2005) Delfgaauw and Dur (2010) and Dal Bò et al. (2013) and interpret intrinsic motivation as a benefit accruing to the worker from being employed in the vocational sector, unrelated to the worker's effort or output. ${ }^{9}$ We denote vocation as $\gamma$ and assume that $\gamma \in[\gamma, \bar{\gamma}]$ with $0=\underline{\gamma}<\bar{\gamma}$. ${ }^{10}$ By slightly

\footnotetext{
${ }^{9}$ Other papers describe motivated workers as people enjoying their personal contribution to the output produced in the vocational market (Besley and Ghatak 2005, Delfgaauw and Dur 2007, 2008, Barigozzi and Burani 2013, 2014).

${ }^{10}$ Our setting is similar to Delfgaauw and Dur's model (2010), where the two sectors are the public (vocational) and the private one. In their model, the two sectors are perfectly competitive and workers' ability and motivation are fully observable.
} 
abusing notation, $\gamma$ will correspond to the monetary equivalent of the vocational premium workers obtain from their job in the vocational sector. Let $F(\theta, \gamma), H(\theta)$ and $G(\gamma)$,respectively, be the cumulative joint distribution function and the marginal distribution functions of the population of potential workers, and let $f(\theta, \gamma), h(\theta)$ and $g(\gamma)$ be their corresponding probability density functions. Average productivity and average vocation are thus $E[\theta]=\int_{\underline{\theta}}^{\bar{\theta}} \theta h(\theta) d \theta=\mu_{\theta}$ and $E[\gamma]=\int_{\underline{\gamma}}^{\bar{\gamma}} \gamma g(\gamma) d \gamma=\mu_{\gamma}$ respectively. ${ }^{11}$

Workers aim at maximizing their labor earnings. In the baseline model, workers receive a uniform wage $w$ in the vocational sector. This assumption has typically two justifications: first, productivity and vocation are workers' private information and no screening mechanisms are available to firms; secondly, in many vocational sectors, contracts are mostly standardized, based upon a uniform wage policy (for instance, teachers in public schools or nurses in public hospitals) and characterized by a series of preestablished steps on the career ladder. In the outside-option sector the worker obtains a payoff $r(\theta)$ which is thus the opportunity cost to a worker of accepting employment in the vocational sector. The function $r(\theta)$ is assumed to be strictly increasing in $\theta$, i.e. $r^{\prime}(\theta)>0$, for example because productivity is rewarded in the outside-option sector. A uniform wage and an outside option rewarding productivity are the necessary ingredients of the well-known Lemons model which allows to study the problem of adverse selection in markets. ${ }^{12}$ However, in the following subsection we will show that this simple Lemons model can be interpreted as the reduced form for other, more general specifications, the most interesting being the one where productivity is rewarded also in the vocational sector.

Potential applicants accept the job in the vocational sector if the total monetary benefit they receive from the job is larger than their outside option. The total monetary benefit to the worker is given by the wage rate $w$ plus the monetary equivalent of the vocational premium $\gamma$. As a consequence, a potential applicant with characteristics $(\theta, \gamma)$ accepts the vocational job if and only if he/she receives a total benefit of at least $r(\theta)$ (for convenience, we assume that the worker accepts the vocational job in case he/she is indifferent), that is if and only if

$$
w+\gamma \geq r(\theta)
$$

Note that the vocational premium $\gamma$ is uniquely obtained when the worker is hired by firms in the vocational market. Thus, all else being equal, the higher the worker's vocation, the higher the total benefit from the job in the vocational sector. ${ }^{13}$

We instead extend their analysis considering asymmetric information on both characteristics of potential applicants.

${ }^{11}$ Barigozzi and Turati (2012) consider the market of nurses in a simpler model with four worker types and provide somehow extreme results because the two counter-intuitive effects always occurs for a subset of wage rates; which one prevails depends on the relative impact that productivity and vocation have on the workers' reservation wages and on their ranking.

${ }^{12}$ See for instance Mas-Colell et al. 1995, chapter 13.

${ }^{13}$ Note that if $\gamma$ is large enough a worker can decide to accept the job in the vocational sector even when the salary is $w=0$, as for volunteer workers or workers engaged in charity work. 
From inequality (1), we observe that potential workers with low productivity $\theta$ are more likely to accept the job (the well-known adverse selection problem on productivity), and potential workers with high vocation $\gamma$ are more likely to accept the job, as firstly discussed in Heyes (2005) and in Delfgaauw and Dur (2007). Our aim is to investigate the interaction between these two phenomena studying a Lemons problem with bidimensional private information.

In the following sections we will compare this Vocational Lemons Model (VLM) model with the Standard Lemons Model (SLM) where intrinsic motivation is irrelevant and does not affect the workers' participation constraint, which is simply given by

$$
w \geq r(\theta)
$$

For the sake of comparison, the population of potential workers is still described by the distribution $F(\theta, \gamma)$ even in the $S L M$.

\subsection{Alternative interpretations}

The simple Vocational Lemons Model can be seen as the reduced form of other interesting environments. As illustrated below, two main specifications are consistent with the basic VLM if some "disadvantage" is attributed to the vocational sector with respect to the alternative one, so that motivated workers still face a trade-off when choosing which sector to enter.

\subsubsection{Incentive scheme in the vocational market}

Workers may still self-select into the vocational or the alternative sector but, differently from above, in both sectors workers' remuneration is characterized by a fixed part plus an incentive scheme of the form

$$
\tilde{w}_{j}(\theta)=\bar{w}_{j}+w_{j}(\theta)
$$

where $j \in\{V, N V\}$, with $V$ referring to the vocational sector and $N V$ to the alternative one, where $\bar{w}_{j}$ is the fixed part of the remuneration whereas $w_{j}(\theta)$ is the incentive scheme that rewards the workers' productivity, being $w_{j}^{\prime}(\theta)>0$.

The workers' participation constraint now becomes

$$
\bar{w}_{V}+w_{V}(\theta)+\gamma \geq \bar{w}_{N V}+w_{N V}(\theta)
$$

where the left-hand side indicates workers' overall remuneration when accepting the job in the vocational sector and the right-hand side the workers' remuneration when working in the alternative sector. Setting $\bar{w}_{V}-\bar{w}_{N V}=w$ and $w_{N V}(\theta)-w_{V}(\theta)=r(\theta)$, allows us to be back to inequality (1). This shows that the results that we will provide with the simple $V L M$ still hold as long as the vocational sector is characterized by lower power of incentives, i.e. $w_{V}^{\prime}(\theta)<w_{N V}^{\prime}(\theta)$, so that $r^{\prime}(\theta)>0$. 
The previous inequality is consistent with the fact that vocational markets are frequently characterized by some institutional constraints and less flexibility in designing wage schemes. Moreover, the tasks that workers are required to perform in vocational markets generally involve some non contractible components so that workers' productivity is often more difficult to measure with respect to alternative sectors and tasks. ${ }^{14}$ Finally, note that low-powered incentives in vocational sectors have been predicted by some theoretical literature (see, as an example, Handy and Katz 1998 and Besley and Gathak 2005).

\subsubsection{Sector-specific disutility from labor}

Another possible extension of the baseline $V L M$ is the following. A uniform remuneration $w_{j}$ is offered in both the vocational and the alternative sectors but workers experience a disutility from labor $r_{j}(\theta)$ which is sector-specific and depends on $\theta$ in such a way that $r_{j}^{\prime}(\theta)<0$. The worker's participation constraint now is:

$$
w_{V}+\gamma-r_{V}(\theta) \geq w_{N V}-r_{N V}(\theta)
$$

The left-hand side indicates the overall worker's utility when accepting the job in the vocational sector, the right-hand side the utility when working in the alternative sector. By writing $w_{V}-w_{N V}=w$ and $r_{V}(\theta)-r_{N V}(\theta)=r(\theta)$ we are back again to inequality (1). We now need that $0>r_{V}^{\prime}(\theta)>r_{N V}^{\prime}(\theta)$, meaning that worker's disutility decreases with productivity faster in the non-vocational sector than in the vocational one.

\section{The Lemons Problem in the vocation-based labor market}

In this Section, we compare the inefficiency caused by adverse selection in the $V L M$, basically described by participation constraint (1) with the SLM described by participation constraint (2).

In the Standard Lemons Model, the workers' entry decision in the relevant market depends on their productivity level $\theta$ in a way that adversely affects the firms operating in that sector. Since the outside option is larger for more capable workers, i.e. since $r^{\prime}(\theta)>0$, only relatively less productive workers are

\footnotetext{
${ }^{14}$ The quality of services is particularly relevant in vocational jobs and is typically non-contractible (although it is observable by the recipients of services) and thus it is not rewarded directly. Consider for example a nurse asked to administer a particular number of injections: the quality of the service he/she provides increases if the injections are administered with "tender loving care". However, a nurse is not rewarded for being tender. Examples of non-contractible quality levels in the market for health professionals are provided in McGuire (2008, page 281): "While time is one concrete candidate for what is meant by non-contractible quality as an input into patient health, diligence, responsiveness, and attentiveness can be thought of in the same category as well.". In the same way, a lecturer can be contracted to deliver a course, but being available for hallway conversation, motivating students and reinforcing their learning process is essentially voluntary and not rewarded. At school, quality of teaching is higher if a teacher promotes curiosity and creative thinking and refines students' oral and written communication skills, but this goes beyond his/her explicit duties.
} 
willing to accept the job in the relevant sector at any given wage; the most productive workers opt-out and are employed in the alternative sector. This translates into an inefficiently low level of output when, for instance, the production technology in the relevant sector is not inferior to the one of the alternative sector.

Let us call marginal workers those workers who are indifferent between accepting the job in the relevant sector or opting out. In the Standard Lemons Model, let $\hat{\theta}$ be the productivity of marginal workers model, i.e. let $\hat{\theta}$ be is such that $r(\hat{\theta})=w$. Thus $\hat{\theta}=r^{-1}(w)$. Similarly, in the Vocational Lemons Model, let $(\tilde{\theta}, \tilde{\gamma})$ be the characteristics of marginal workers, i.e. let $(\tilde{\theta}, \tilde{\gamma})$ be such that $r(\tilde{\theta})=w+\tilde{\gamma}$. Thus, $\tilde{\theta}=r^{-1}(w+\tilde{\gamma})$. Note that $\tilde{\theta}=\hat{\theta}$ for $\tilde{\gamma}=0$.

Definition 1 Given a salary $w_{0}$, in the VLM, the curve of marginal workers is

$$
\gamma(\theta)=r(\theta)-w_{0}
$$

In Figure 1, the set of potential workers is represented in the plane $(\theta, \gamma)$ for a concave function $r(\theta)$. The curve of indifferent workers splits the set of potential workers into two regions and $r(\theta)$ and $w_{0}$ are such that $\theta_{\text {sup }}=r^{-1}\left(w_{0}+\bar{\gamma}\right)<\bar{\theta}$, where $\theta_{\text {sup }}$ is the highest productivity level of workers accepting the job in the vocational sector for a given salary $w_{0} .{ }^{15}$ Obviously, the shaded area indicates all types accepting the job in the vocational sector given the salary $w_{0}$, the complementary region indicates types refusing the firms' offers and opting out. ${ }^{16}$

Insert Figure 1 around here

Note that, in the $S L M$, given a salary $w_{0}$, active workers in the standard sector are simply indicated by the rectangle with sides $\left(r^{-1}\left(w_{0}\right)-\underline{\theta}\right)$ and $\bar{\gamma}$ (see again Figure 1).

Observation 1 Given a salary $w_{0}$, both employment and average productivity of active workers in the relevant sector are higher in the VLM than in the SLM: $E_{V L M}\left[\theta \mid w_{0}\right]>E_{S L M}\left[\theta \mid w_{0}\right]$.

Proof. See Appendix A.1.

The previous observation implies that adverse selection has a stronger impact in the SLM than in the $V L M$. Namely, whatever is the degree of inefficiency observed in the SLM, such inefficiency is necessarily reduced in the VLM. In particular, by defining the function $\check{r}(\theta)$ characterized by $\check{r}^{-1}\left(w_{0}\right)=r^{-1}\left(w_{0}\right)$ and $\check{r}(\theta) \leq r(\theta) \forall \theta$, we are then able to add what follows.

\footnotetext{
${ }^{15}$ Depending on the function $r(\theta)-w_{0}, \theta_{\text {sup }}$ can be lower or equal to $\bar{\theta}$. In other words, $\theta_{\text {sup }} \equiv \min \left\{r^{-1}\left(w_{0}+\bar{\gamma}\right), \bar{\theta}\right\}$.

${ }^{16}$ A similar graphical representation is provided in Delfgaauw and Dur (2010) in the case of full information on workers' characteristics and endogenous reservation wage (see also Footnote 10).
} 
Corollary 1 (i) Workers' motivation reduces the inefficiency caused by adverse selection with respect to the SLM. (ii) Conditional on a given wage rate $w_{0}$, the outside-option function $r(\theta)$ is associated with a level of efficiency lower than $\check{r}(\theta)$.

Proof. (i) Directly follows from Observation 1. (ii) Given all $\gamma \in[\underline{\gamma}, \bar{\gamma}]$, the larger $r^{-1}\left(w_{0}+\gamma\right)$, the larger the number of workers with $\theta>\hat{\theta}=r^{-1}\left(w_{0}\right)$ preferring to enter the relevant sector rather than the outside option sector and, thus, the lower the production inefficiency due to adverse selection. The number of workers with $\theta>r^{-1}\left(w_{0}\right)=\check{r}^{-1}\left(w_{0}\right)$ entering the relevant market is higher with $\check{r}(\theta)$ than with $r(\theta)$.

Corollary 1 shows that the outside-option function $r(\theta)$ plays a crucial role in defining the extent of the difference between average productivity of active workers in the $V L M$ and average productivity in the SLM. In particular, we observe that, the flatter is the curve, the larger the average productivity of active workers in the $V L M$.

The intuition behind this result can be outlined as follows. Consider a set of potential workers with high ability and high motivation and their decision whether to enter the vocation-based market or not at a wage rate $w_{0}$. Potential workers with high ability and high vocation receive the wage $w_{0}$ which does not reward their high level of productivity. Nevertheless, they obtain their (high) vocational premium. When the reservation wage function is almost flat, the return to skills outside the vocational sector is low. This implies that, in the alternative sector, an increase in productivity has a minor impact on the workers' payoff. Thus, working in the vocational sector becomes more attractive. When, on the contrary, the reservation wage function is steep, the return to skills outside the vocational sector is high so that working in the vocational sector becomes less attractive.

Note that, if the return to skills outside the vocational sector was completely flat, i.e. if $r(\theta)$ was a horizontal line and the salary was uniform both inside and outside the vocational sector, then production inefficiencies due to adverse selection would be the lowest possible. Finally, consider the opposite extreme case in which the return to skills outside the relevant sector is assumed to be infinitely high (i.e. suppose $r(\theta)$ is a vertical line). In this case, vocation would not affect workers' decision on whether to accept the job in the vocational sector or opt out. Thus, production inefficiencies due to adverse selection would be the same in the $V L M$ and in the $S L M$.

\section{How the wage rate affects the pool of active workers}

We study here how the composition of the active work-force in the vocational sector changes with the wage rate. ${ }^{17}$ This analysis will provide important insights to understand labor supply in vocational labor

\footnotetext{
${ }^{17}$ To justify that the workers' reservation wage $r(\theta)$ remains fixed also when salary in the vocation-based sector changes, we assume that the size of the vocation-based sector is small with respect to the outside-option sector. Thus, changes in
} 
markets.

Note that, as the wage rate marginally increases and shifts to $w_{0}+d w_{0}$, the curve of indifferent workers $\gamma(\theta)=r(\theta)-w_{0}$ moves towards the bottom-right side of Figure 1. Thus, as the wage rate increases, we expect that workers with lower and lower vocation enter the vocational market, or that the impact on the average vocation of active workers is negative. In the same way, we expect that workers with higher and higher productivity enter the vocational market, so that we expect that the average productivity of active workers increases in the wage rate. ${ }^{18}$ However, we are going to see that the interplay of vocation and productivity in the workers' participation constraint determines workers' willingness to accept the job, so that the counter-intuitive cases are also possible: average vocation can be increasing and average productivity can be decreasing in the wage rate.

We first show that average productivity of active workers in the relevant sector is always increasing in the wage rate in the $S L M$. We will then analyze the case of the VLM.

Remark 1 In the SLM, (i) the impact of a marginal increase in wage on marginal workers' productivity $\hat{\theta}=r^{-1}\left(w_{0}\right)$ is positive and equal to $\frac{1}{r^{\prime}(\hat{\theta})}$. (ii) Average productivity of active workers in the standard sector is monotonically increasing in the wage.

Proof. See the Appendix A.2.

When the salary increases, more productive workers accept the job in the SLM and average productivity among active workers monotonically increases (see the dotted line in Figure 2).

Insert figure 2 around here

We now turn to the $V L M$. We will show that the association between $\theta$ and $\gamma$ is crucial in determining whether counter-intuitive effects occur.

From Observation 1 we know that, for every value of $w$, the average productivity of active workers is weakly larger in the $V L M$, i.e. $E_{V L M}[\theta \mid w] \geq E_{S L M}[\theta \mid w]$. Thus, as Figure 2 shows, the function $E_{V L M}[\theta \mid w]$ necessarily lies above the function $E_{S L M}[\theta \mid w]$. The dashed curve shows the case in which $E_{V L M}[\theta \mid w]$ is monotonically increasing in the wage rate and the continuous curve the case in which the counter-intuitive effect $(i)$ for average productivity occurs for every value of the possible wage rates, or in which $E_{V L M}[\theta \mid w]$ is monotonically decreasing in the wage rate.

To understand why counter-intuitive effects may occur, consider the following special case.

Example 1 Perfect correlation between $\theta$ and $\gamma$ and linear $r(\theta)$. Suppose that the correlation between ability and motivation is perfect, i.e. all potential applicants can be represented through the line $\gamma(\theta)=\theta^{-1}(\gamma)$, and suppose that $r(\theta)$ is linear.

wage in the small sector do not affect wages in the larger one.

${ }^{18}$ See Remark 4 below. 
- Average productivity of active workers. Consider the line $\gamma \equiv \gamma(\theta)$. Marginal workers are defined by $w=r(\theta)-\gamma(\theta)$. By totally differentiating the previous equation we obtain: $\frac{d \theta}{d w}=$ $\frac{1}{r^{\prime}(\theta)-\gamma^{\prime}(\theta)}$. Thus, $\gamma^{\prime}(\theta)<0$ is a sufficient condition such that $\frac{d \theta}{d w}>0$, whereas $\gamma^{\prime}(\theta)>0$ is a necessary condition such that $\frac{d \theta}{d w}<0$. Moreover, $\frac{d \theta}{d w}<0$ if and only if $r^{\prime}(\theta)<\gamma^{\prime}(\theta)$.

- Average vocation of active workers. Consider the line $\theta \equiv \theta(\gamma)$. Marginal workers are defined by $w=r(\theta(\gamma))-\gamma$. By totally differentiating the previous equation we obtain: $\frac{d \gamma}{d w}=\frac{1}{r^{\prime}(\theta) \theta^{\prime}(\gamma)-1}$. Thus, $\theta^{\prime}(\gamma)<0$ is a sufficient condition such that $\frac{d \gamma}{d w}<0$, whereas $\theta^{\prime}(\gamma)>0$ is a necessary condition such that $\frac{d \gamma}{d w}>0$. Moreover, $\frac{d \gamma}{d w}>0$ if and only if $r^{\prime}(\theta)>\frac{1}{\theta^{\prime}(\gamma)}=\gamma^{\prime}(\theta)$.

The previous example shows that counter-intuitive effects can be observed only when the correlation between ability and motivation is positive. Moreover, the two counter-intuitive effects $\left(\frac{d \theta}{d w}<0\right.$ and $\left.\frac{d \gamma}{d w}>0\right)$ do not occur jointly: either applicants' average productivity is decreasing or average intrinsic motivation is increasing in the salary. Finally, the counter-intuitive effects displayed by the $V L M$ depend on the relative magnitude of the slopes of the line of marginal workers $r^{\prime}(\theta)$ and the line of potential workers $\gamma^{\prime}(\theta)$. In fact, when $r^{\prime}(\theta)>\gamma^{\prime}(\theta)>0$, the net reservation wage $r(\theta)-\gamma$ of workers with low skills and low motivation is lower than the net reservation wage of workers with high skills and high motivation ${ }^{19}$. As a consequence, as the wage rate increases, types with higher and higher skills and higher and higher motivation progressively enter the vocational market. On the contrary, when $\gamma^{\prime}(\theta)>r^{\prime}(\theta)>0$, workers with high skills and high motivation have a lower net reservation wage than workers with low skills and low motivation, so that, as the wage increases, the quality of workers progressively deteriorates in the vocational sector.

The following remark summarizes the previous observations.

\section{Remark 2 Perfect correlation between $\theta$ and $\gamma$ and linear $r(\theta)$.}

(a) A negative correlation between ability and motivation is a sufficient condition for the two intuitive effects: $E[\theta \mid w]$ is monotonically increasing and $E[\gamma \mid w]$ is monotonically decreasing in the wage rate.

(b) A positive correlation between ability and motivation is a necessary and sufficient condition for one of the two counter-intuitive effects to occur: $(i)$ if $\gamma^{\prime}(\theta)>r^{\prime}(\theta)>0$, then both $E[\theta \mid w]$ and $E[\gamma \mid w]$ are monotonically decreasing in the wage rate; conversely (ii) if $r^{\prime}(\theta)>\gamma^{\prime}(\theta)>0$, then both $E[\theta \mid w]$ and $E[\gamma \mid w]$ are monotonically increasing in the wage rate.

\footnotetext{
${ }^{19}$ Take two points (workers) $\left(\theta_{1}, \gamma_{1}\right)$ and $\left(\theta_{2}, \gamma_{2}\right)$ on the line $\gamma(\theta)$, where $\theta_{2}>\theta_{1}, \gamma_{2}>\gamma_{1}$ and $\gamma^{\prime}(\theta)>0$. Net reservation wages for the workers represented by the two previous points are: $r\left(\theta_{1}\right)-\gamma_{1}$ and $r\left(\theta_{2}\right)-\gamma_{2}$, respectively. The inequality $r^{\prime}(\theta)>\gamma^{\prime}(\theta)$ implies that $r\left(\theta_{2}\right)-r\left(\theta_{1}\right)>\gamma_{2}-\gamma_{1}$ or that the net reservation wage of worker 2 is larger than that of worker 1. Similarly, inequality $r^{\prime}(\theta)<\gamma^{\prime}(\theta)$ implies that the net reservation wage of worker 1 is larger than that of worker 2 .
} 
Example 1 and the above Remark 2 already generalize the results of the theoretical model presented in Dal Bò et al. (2013). In their Proposition 1, they state that "an increase in wages increases the average ability of the applicant pool" and that it also increases the average motivation of the pool if a perfect, positive and strong correlation between ability and motivation exists. Such results, together with the conditions guaranteeing them, perfectly parallel those described in part $b(i i)$ of Remark 2. Differently from Dal Bò et al. (2013), our Example 1 also shows that a positive association between ability and motivation is fully compatible with the more striking case of average ability of active workers being decreasing in the wage rate (see part $b(i)$ of the Remark 2). But there is much more to that.

In Proposition 1 below, we provide sufficient conditions that allow for counter-intuitive effects in the $V L M$ to occur, where we consider a general joint probability distribution for $\theta$ and $\gamma$ and a non-linear function $r(\theta)$.

The proof of the Proposition is based on the observation that a sufficient condition for $E_{V L M}[\theta \mid w]$ being decreasing in $w$ for a non-empty set of wage levels is that there exists a salary $w_{0}$ such that $E_{V L M}\left[\theta \mid w_{0}\right]>\mu_{\theta}$. In fact, $E_{V L M}[\theta \mid w]$ converges to $\mu_{\theta}$ for $w$ sufficiently high. In the same way, a sufficient condition for $E_{V L M}[\gamma \mid w]$ being increasing in $w$ for a non-empty set of wage levels is that a salary $w_{00}$ exists such that $E_{V L M}\left[\gamma \mid w_{00}\right]<\mu_{\gamma}$; in fact, $E_{V L M}[\gamma \mid w]$ converges to $\mu_{\gamma}$ for $w$ sufficiently high.

We first introduce the following definition.

Definition 2 (a) Let $A_{1, w_{0}} \cup A_{2, w_{0}}$ denote the set of all workers entering the vocational market at the salary $w_{0}$. Let $A_{1, w_{0}}$ be the subset of workers with productivity below the population average, i.e. such that $\theta \leq E[\theta]=\mu_{\theta}$; instead, let $A_{2, w_{0}}$ be the subset of workers with productivity above the population average, i.e. $\theta \geq E[\theta]=\mu_{\theta}$.

(b) In the same way, let $B_{1, w_{00}} \cup B_{2, w_{00}}$ denote the set of all workers entering the vocational market at the salary $w_{00}$. Let $B_{1, w_{00}}$ be the subset of workers with motivation below the population average, i.e. such that $\gamma \leq E[\gamma]=\mu_{\gamma}$; instead, let $B_{2, w_{00}}$ be the subset of workers with motivation above the population average, i.e. $\gamma \geq E[\gamma]=\mu_{\gamma}$.

It immediately follows from the above definition that: (a) $E\left[\theta \mid A_{2, w_{0}}\right]>\mu_{\theta}$ and $E\left[\theta \mid A_{1, w_{0}}\right]<\mu_{\theta}$ and $P\left(A_{1, w_{0}}\right)=1-P\left(A_{2, w_{0}}\right)$, where $P$ denotes the probability associated with each subset; $(b) E[\gamma \mid$ $\left.B_{2, w_{00}}\right]>\mu_{\gamma}$ and $E\left[\theta \mid B_{1, w_{00}}\right]<\mu_{\gamma}$; moreover, $P\left(B_{2, w_{00}}\right)=1-P\left(B_{1, w_{00}}\right)$.

\section{Proposition 1 (Sufficient conditions for counter-intuitive results)}

- If a wage $w_{0}$ exists such that

$$
\frac{P\left(A_{2, w_{0}}\right)}{1-P\left(A_{2, w_{0}}\right)} \geq-\frac{E\left[\theta \mid A_{1, w_{0}}\right]-\mu_{\theta}}{E\left[\theta \mid A_{2, w_{0}}\right]-\mu_{\theta}}
$$


then $E\left[\theta \mid w_{0}\right]>\mu_{\theta}$ and a non-empty subset of wage levels exists in which $E[\theta \mid w]$ is decreasing in the wage rate.

- If a wage $w_{00}$ exists such that

$$
\frac{P\left(B_{1, w_{00}}\right)}{1-P\left(B_{1, w_{00}}\right)} \geq-\frac{E\left[\gamma \mid B_{2, w_{00}}\right]-\mu_{\gamma}}{E\left[\gamma \mid B_{1, w_{00}}\right]-\mu_{\gamma}}
$$

then $E\left[\gamma \mid w_{00}\right]<\mu_{\gamma}$ and a non-empty subset of wage levels exists in which $E[\gamma \mid w]$ is increasing in the wage rate.

Proof. See Appendix A.3.

Note that the left-hand side of inequality (3) is always positive and unbounded, whereas the quantity on the right-hand side is positive and finite as long as $\mu_{\theta}<\infty$. So, a salary $w_{0}$ that satisfies the condition may exist. Indeed, in the simulations briefly discussed in the next subsection, we show that condition (3) can be verified for the whole set of wage levels.

Similarly, the left-hand side of inequality (4) is always positive and unbounded, whereas the quantity on the right-hand side is positive and finite as long as $\mu_{\gamma}<\infty$. So, again, a wage $w_{00}$ that satisfies the condition may exist. Again, in the simulations we show that condition (4) can be verified for the whole set of wage levels.

Inequality (3) states that, for a given wage rate $w_{0}$, the counter-intuitive effect on the average productivity of active workers in the vocational sector occurs if: (i) the probability of observing highly productive workers $P\left(A_{2, w_{0}}\right)$ is greater than the probability of observing below-average productivity workers, $1-P\left(A_{2, w_{0}}\right)$; $(i i)$ the ratio of the two previous probabilities is greater than the ratio of the distances of the two conditional means, $E\left[\theta \mid A_{1, w_{0}}\right]$ and $E\left[\theta \mid A_{2, w_{0}}\right]$, with respect to the marginal mean. Thus, not only should the probability $P\left(A_{2, w_{0}}\right)$ be large enough to yield $E[\theta \mid w]$ decreasing in wage, but the average $\theta$ in $A_{2, w_{0}}$ should be sufficiently greater than $\mu_{\theta}$, while the average $\theta$ in $A_{1, w_{0}}$ has to be close enough to $\mu_{\theta}$. In a nutshell, condition (3) requires a large number of applicants in the vocational sector characterized by an average productivity sufficiently greater than the population average $\mu_{\theta}$.

Condition (4) follows the same logic and requires a sufficiently large number of applicants in the vocational sector characterized by an average motivation sufficiently lower than the population average $\mu_{\gamma}$.

Note that condition (3) requires a positive association between $\theta$ and $\gamma$ conditional on $w_{0}$. Similarly, condition (4) asks for a positive association between $\theta$ and $\gamma$ conditional on $w_{00}$. In turn, both conditions are consistent with the hypothesis of a strong positive association between $\theta$ and $\gamma$. In fact, condition (3) requires a large mass in the upper-right part of the set of potential workers, while condition (4) holds if a large mass is associated with the bottom-left part of the set of potential workers. 
Moreover, if the distribution of $\theta$ and $\gamma$ is characterized by a positive association, then we must conclude that the two counter-intuitive effects cannot occur together.

Remark 3 Suppose a positive association between ability and motivation exists. As the wage rate increases, $E[\theta \mid w]$ and $E[\gamma \mid w]$ must move in the same direction: either both increase or both decrease.

In fact, (3) implies that workers entering the market for a salary larger than $w_{0}$ are characterized by below-average productivity levels. Then $E[\theta \mid w]$ falls. Furthermore, if $\operatorname{cov}\left(\theta, \gamma \mid w_{0}\right)>0$ also workers with vocation levels below the average are simultaneously entering the market and then $E\left[\gamma \mid w>w_{0}\right]$ must also decrease. Similarly, if condition (4) holds, workers with above-average motivation are entering the market for wages larger than $w_{00}$ and then $E[\gamma \mid w]$ must increase. However, a positive covariance between $\theta$ and $\gamma$ conditional on $w_{00}$ implies that workers with above-average productivity are entering the market as well. As a consequence, $E\left[\theta \mid w>w_{00}\right]$ must also increase. Thus, the two counterintuitive effects cannot occur together. ${ }^{20}$

Following the same reasoning, when the association between $\theta$ and $\gamma$ is negative and when we consider active workers conditional on the wage $w_{0}$, then either $E\left[\theta \mid w>w_{0}\right]$ is increasing and $E\left[\gamma \mid w>w_{0}\right]$ is decreasing in wage, or the opposite pattern occurs. As already mentioned, we expect both intuitive effects to occur in the latter case. The following remark confirms our intuition.

Remark 4 Intuitive effects are consistent with a negative association between productivity and motivation.

Proof. See Appendix A.4.

In the following Section and in line with Remark 2, we provide a simple and intuitive condition to discriminate between the two counter-intuitive cases (decreasing average ability and increasing average motivation), which is based on the relative magnitude of the correlation between $\theta$ and $\gamma$ and of the slope of the return to ability $r(\theta)$.

Finally, let us underline the relationship between the results contained in this section and in the previous one. Corollary 1 states that intrinsic motivation leads to an overall increase in the average productivity of active workers so that $E_{V L M}[\theta \mid w]$ lies above $E_{S L M}[\theta \mid w]$ for every possible $w$ and inefficiencies due to adverse selection are mitigated. In general, the distance between $E_{V L M}[\theta \mid w]$ and $E_{S L M}[\theta \mid w]$ decreases with the wage rate and goes to zero when the wage is so high that all potential workers enter the relevant market in both models. Obviously, the distance between the two curves also

\footnotetext{
${ }^{20}$ Contrasting again our analysis with Dal Bò et al. (2013), note that Condition (4), which implies that a non-empty subset of wage levels exists such that $E[\gamma \mid w]$ is increasing in $w$, generalizes the theoretical predictions of their model to a general joint distribution of worker's ability and motivation. Moreover, we are also able to explain the striking counter-intuitive result generated by Condition (3).
} 
depends on whether Condition (3) is or is not verified. This can be seen in Figure 2. The monotonically decreasing curve indicates $E_{V L M}[\theta \mid w]$ when Condition (3) holds for every value of the wage rate, whereas the monotonically increasing dashed curve describes the intuitive case. In particular, when $E_{V L M}[\theta \mid w]$ decreases in the wage rate, the distance between $E_{V L M}[\theta \mid w]$ and $E_{S L M}[\theta \mid w]$ is larger and intrinsic motivation reduces adverse selection inefficiencies even more. Intuitively, this occurs since the distribution of productivity and motivation in the population of potential workers is such that a large number of workers with high ability and high motivation enter the vocational market for low levels of the wage rate. Conversely, for the same wage levels, only low-productivity workers enter the relevant market in the $S L M$.

\subsection{Linear relationship between $\theta$ and $\gamma$}

In the previous section we considered two extreme cases: perfect correlation between $\theta$ and $\gamma$ (see Example 1) and a general distribution of $\theta$ and $\gamma$ (see Proposition 1). In this subsection, we deal with the convenient and practical case of a linear relationship between the two variables. We first briefly discuss the results from some simulations (that are described in detail in Appendix A.5) and then we re-interpret the statement of Proposition 1.

In Appendix A.5, we considered a sample of 200,000 subjects with characteristic $\left(\theta_{i}, \gamma_{i}\right)$ from a truncated bivariate Gaussian random variable defined in $[\underline{\theta}, \bar{\theta}] \times[\underline{\gamma}, \bar{\gamma}]$, such that $E[\theta]=\frac{\underline{\theta}+\bar{\theta}}{2}$ and

$E[\gamma]=\frac{\gamma+\bar{\gamma}}{2}$. The curve of marginal workers is linear. A linear dependence between $\theta$ and $\gamma$ exists and the sign of the slope of the regression line, $b$, is determined by the sign of $\operatorname{cov}(\theta, \gamma)$. Expected values of $\gamma$ and $\theta$ given the wage level $w$ are computed through Monte Carlo integration.

Panels A and D in Figure 3 show a case where $E[\theta \mid w]$, as well as $E[\gamma \mid w]$, is monotonically decreasing in $w$. This means that Condition (3) is verified for all $w$. Panel $\mathrm{B}$, instead, shows a case where $E[\theta \mid w]$ and $E[\gamma \mid w]$ are both monotonically increasing, implying that Condition (4) is verified for all the possible values of the wage rate. Finally, panel $\mathrm{C}$ depicts intuitive effects.

To obtain the four scenarios described in Figure 3, we changed the covariance between $\theta$ and $\gamma$, the slope of the regression line and the slope of the outside option function. In particular, panels A, B and $\mathrm{D}$ are obtained by taking $\operatorname{cov}(\theta, \gamma)>0$, panel $\mathrm{C}$ by choosing $\operatorname{cov}(\theta, \gamma)<0$. According to Remark 2 , to obtain panels $\mathrm{A}$ and $\mathrm{D}$, we have chosen a slope of the outside option function lower than that of the regression line; the opposite to obtain panel B.

\section{Insert Figure 3 about here}

We are now able explain the link between Conditions (3) and (4) in Proposition 1 and the conditions outlined in Remark 2. We consider here Case A, which is characterized by both $E[\theta \mid w]$ and $E[\gamma \mid w]$ decreasing in the wage rate; Case B is treated in Appendix A.5. In Figure 4, the whole set of potential 
workers is represented, together with the average values of $\theta$ and $\gamma$, the regression line and the line of marginal workers defined by a wage rate set equal to 3 . The line of marginal workers divides the set of active workers into the two subsets, $A_{1, w_{0}=3}$ and $A_{2, w_{0}=3}$, described in Definition 2. Figure 4 shows that Condition (3) is likely to be verified for $w_{0}=3$, because $P\left(A_{2, w_{0}=3}\right)$ is larger than $\left(1-P\left(A_{2, w_{0}=3}\right)\right)$. Moreover, the subset $A_{2, w_{0}=3}$ clearly contains the more skilled and more motivated workers so that, when the wage rate increases, workers with lower skills and lower motivation will necessarily enter the market. Finally, note that Condition (4) is not verified for $w_{0}=3, P\left(B_{1, w_{0}=3}\right)$ being clearly lower than $\left(1-P\left(B_{1, w_{0}=3}\right)\right)$.

Insert Figure 4 about here

Interestingly, for a given $w_{0}$ and a linear dependence in mean between $\theta$ and $\gamma$, a large mass in the subset $A_{2, w_{0}}$ (or a positive conditional covariance between the two variables, $\operatorname{cov}\left(\theta, \gamma \mid w_{0}\right)>0$ ) is consistent with the following two features: $(i)$ a positive covariance, $\operatorname{cov}(\theta, \gamma)>0$, and $(i i)$ a slope of the regression line that is larger than the slope of the line of marginal workers. In fact, as Figure 4 shows, when the slope of the regression line is larger than the slope of the line of marginal workers, then a large mass of workers, that are active in the vocational market given $w_{0}$, is located in the upper-right part of the whole set of workers. Of course, $(i)$ and (ii) are not sufficient to prove Proposition 1 because they do not contain information on the gap between the conditional mean and the marginal mean, $E\left[\theta \mid A_{i, w_{0}}\right]$ and $\mu_{\theta}$, respectively. However, $(i)$ and (ii) provide some practical conditions suggesting when inequality (3) is satisfied.

In Example 1, because of perfect correlation, a positive covariance is necessary and sufficient to ensure that one counter-intuitive result occurs; the relative magnitude of the slope of the line of marginal workers and that of the regression line determines which one of the two effects realizes. On the contrary, for a more general distribution function, a positive covariance and the relative magnitude of the two slopes are no longer sufficient conditions. Thus, we can state the following:

Remark 5 Assume a linear relationship between $\theta$ and $\gamma$, that is let $\gamma=a+b \theta+\tilde{\varepsilon}$, where $\tilde{\varepsilon}$ is an error term with zero mean and $b=\frac{\operatorname{cov}(\theta, \gamma)}{\operatorname{var}(\theta)}$. When $\operatorname{cov}(\theta, \gamma)>0$, then one of two counter-intuitive results may occur: $(i)$ when $r^{\prime}(\theta)<b$, average productivity of active workers can be decreasing in the wage rate for a non-empty subset of wage levels; (ii) when $r^{\prime}(\theta)>b$, average vocation of active workers can be increasing in the wage rate for a non-empty subset of wage levels.

As discussed in Subsection 2.1.1, note that our results can be naturally extended to a vocational market where incentive schemes are in place, provided that the return to ability is lower in the vocational market than in the non-vocational one. In this case, $r^{\prime}(\theta)$ must be interpreted as the difference in the power of incentives offered by firms in the two sectors. 
Finally, observe that, in the simulations, the return to ability has been assumed to be linear, implying that, for every $\theta$, either $r^{\prime}(\theta)<b$ or $r^{\prime}(\theta)>b$ is true and that monotonicity of $E[\theta \mid w]$ and $E[\gamma \mid w]$ is possible. Instead, when $r^{\prime \prime}(\theta) \neq 0$, we expect more complicate patterns since the relative magnitude of $r^{\prime}(\theta)$ and $b$ might well change with $\theta$. This prevents monotonicity but does not affect our results.

In Appendix A.6, we provide some evidence that productivity and motivation are characterized by a positive conditional dependence $\operatorname{cov}\left(\theta, \gamma \mid w_{0}\right)>0$, using data provided by the Italian survey ICSI 2007.

In particular, we consider the employees of the Italian cooperatives analyzed in the survey, that is, workers that entered the vocational market at a given salary. The ICSI survey includes the question "How do you define your employer-employee relationship with the cooperative?", the answer to which can be considered as a proxy for workers' motivation. Moreover, as a proxy for the workers' productivity, we consider bonuses and cash prizes that they receive as an extra earning with respect to their monthly wage. ${ }^{21}$ It is worth noting that we do not interpret the association between motivation and productivity as causal, but simply as documenting their statistical connection.

\subsection{Policy implications: an example}

Suppose that, given the current wage scheme in place in the vocational sector, the policy-maker observes a shortage of workers, as it actually occurs in the market for nurses in many countries ${ }^{22}$. Our paper shows that a wage increase as a policy to deal with the shortage has an important potential drawback. Indeed, when Condition (3) holds, the average ability of active workers can deteriorate, since higher salaries may attract less skilled workers. This undesirable outcome, that a policy-maker is willing to avoid, occurs when a positive and strong association between skills and vocation exists. Moreover, not only do higher salaries trigger a decrease in the average ability of the work-force, but also a decrease of average motivation: thus increasing wages deteriorates the quality of workers with respect to both dimensions.

The statistical relationship between motivation and productivity in the case of potential nurses could be measured using data collected, for example, from students attending nursing schools. ${ }^{23}$ Our analy-

\footnotetext{
${ }^{21}$ Our empirical results are coherent with the literature on public administration showing that public service motivation is positively correlated with job performance in the public sector (see Petrovsky 2009, Naff and Crum 1999, Park and Rainey 2008, Ritz 2009 and Steijn 2008). Moreover, Freeman (1997) finds evidence of positive dependence between productivity and vocation. The author considers volunteer workers, or the ones who are willing to work for nothing. In our model they are the ones with either a very high motivation or a very low outside option, or both. He shows that volunteers are indeed workers with high productivity and characterized by a high opportunity-cost to engage in the working-for-nothing activity. This suggests that many potential workers with characteristics close to $(\bar{\theta}, \bar{\gamma})$ exist, so that a positive dependence between productivity and vocation may result at least for high-productivity levels.

22 See, among others, Antonazzo et al. 2003; Shields 2004; Simoens et al. 2005.

${ }^{23}$ See Amabile et al. (1994) for a Work Preference Inventory consisting of 30 questions designed to assess college students'
} 
sis indicates that, given a negative association between motivation and productivity conditional on the wage, higher salaries will attract nurses with higher skills but lower motivation. Given a positive association, instead, we are able to distinguish between the two counter-intuitive results. In particular, a low (strong) positive association between ability and motivation is likely to correspond to a positive (negative) relationship between the wage rate and the ability of active workers.

Another example from the market for politicians is briefly mentioned in the Conclusion which follows.

\section{Conclusion}

Do higher salaries always attract more productive workers? We have shown that this is not necessarily the case when workers are heterogeneous with respect to two characteristics, productivity and motivation.

Our theoretical analysis identifies simple conditions such that a negative relationship between the wage rate and workers' ability exists, based on the distribution of the two characteristics in the population of potential workers. In particular, when there is a negative association between workers' ability and motivation and when the two characteristics are independently distributed, the intuitive scenario occurs where wages attract more productive but less motivated workers. When the correlation between workers' ability and motivation is positive but not too strong, then a wage increase attracts more productive workers (as expected), and also the more motivated ones, the best scenario. With a sufficiently strong and positive correlation between productivity and motivation, a wage increase may have a serious drawback because it attracts not only less motivated workers, but also less productive employees.

As such, our model provides a general and unifying explanation about apparently contrasting evidence documented in different environments, which the theoretical literature studying vocational sectors was still missing. Namely, our results account for why increasing the wage rate attracts more skilled teachers and civil servants but (in some cases) less productive politicians.

Our findings have also important policy implications. For instance, in some countries, it is currently debated whether remuneration of elected representatives should be reduced. Since the existing evidence has shown (in the European Union and Italy) that higher remuneration tends to be associated with less skilled Members of Parliaments, our model suggests that a reduction in the parliamentary wage could be indeed an appropriate policy measure not only to reduce inequity, as the advocates of the reform assert, but also to increase the quality of politicians. The effects of wage policies ultimately rest on the correlation between ability and vocation in the population of potential workers, so that these policies should be supported by sector-specific knowledge of the association properties of the two characteristics. overall intrinsic and extrinsic motivation toward their work. 


\section{References}

[1] Amabile T.M., K.G. Hill, B.A. Hennessey and E.M. Tighe (1994), "The Work Preference Inventory: Assessing Intrinsic and Extrinsic Motivational Orientations", Journal of Personality and Social Phycology, 66(5), 950-967.

[2] Antonazzo E., Scott A., Skatun D., and Elliott R. F. (2003), "The labour market for nursing: a review of the labour supply literature", Health Economics, 12, 465-478.

[3] Bargain, O. and B. Melly (2008), "Public Sector Pay Gap in France: New Evidence Using Panel Data". IZA Discussion Paper No. 3427.

[4] Barigozzi, F. and G. Turati (2012), "Human Health Care and Selection Effects. Understanding Labour Supply in the Market for Nursing", Health Economics, 21(4), 477- 483.

[5] Barigozzi, F. and N. Burani (2013), "Bidimensional Screening with Intrinsically Motivated Workers", working paper n. 866, Department of Economics, University of Bologna.

[6] Barigozzi, F. and N. Burani (2014), "Competition and Screening with Skilled and Motivated Workers", working paper n. 953, Department of Economics, University of Bologna.

[7] Becchetti L., S. Castriota, E. Tortia (2009), "Productivity, Wages and Intrinsic Motivation in Social Enterprises", AICCON working paper 22/12/2009 n.66. Available at http://www.aiccon.it/file/convdoc/wp_aiccon_intrinsicmotivation.pdf

[8] Besley, T. (2004), "Paying Politicians: Theory and Evidence". Journal of the European Economic Association, 2, 193-215.

[9] Besley, T. (2005), "Political Selection". Journal of Economic Perspective, 119(3), 43-60.

[10] Besley T., Ghatak M. (2005), "Competition and Incentives with Motivated Agents", American Economic Review 95(3), 616-636.

[11] Caselli, F. and Massimo Morelli (2004) "Bad Politicians". Journal of Public Economics, 88, 759-782.

[12] Corcoran S.P., W.N. Evans, R.M. Schwab (2004), "Changing Labor-Marker Opportunities for Women and the Quality of Teachers, 1957-2000", AEA Papers and Proceedings, 94(2), 230-235.

[13] Dal Bò, E., F. Finam and M. Rossi (2013), "Strengthening State Capabilities: The Role of Financial Incentives in the Call to Public Service", Quarterly Journal of Economics, 128(3), 1169-1218.

[14] Delfgaauw J. and R. Dur (2007), "Signaling and screening of workers' motivation", Journal of Economic Behavior and Organization, 62, 605-624. 
[15] Delfgaauw J. and R. Dur (2008), "Incentives and workers' motivation in the public sector", The Economic Journal, 118, 171-191.

[16] Delfgaauw J. and R. Dur (2010), "Managerial talent, motivation, and self-selection into public management", Journal of Public Economics, 94(9-10), 654-660.

[17] Dolton P. and O.r Marcenaro-Gutierrez (2011) "If You Pay Peanuts, Do You Get Monkeys? A Cross-country Analysis of Teacher Pay and Pupil Performance", Economic Policy, 26(65), 5-55.

[18] Ferraz C. and Finam F. (2011), "Motivating Politicians: The Impacts of Monetary Incentives on Quality and Performance", NBER Working Paper No. 14906.

[19] Fisman R., N.A. Harmon, E. Kamenica, and I. Munk (2012), "Labor Supply of Politicians", NBER Working Paper No. 17726.

[20] Francois P. (2000), "Public service motivation' as an argument for government provision", Journal of Public Economics, 78(3), 275-299.

[21] Freeman, R. (1997) "Working for Nothing: the Supply of Volunteer Labor", Journal of Labor Economics, 15, 140-166.

[22] Gagliarducci S. and T. Nannicini (2013), "Do Better Paid Politicians Perform Better? Disentangling Incentives from Selection", Journal of the European Economic Association, 11(2), 369-398.

[23] Leete L. (2001), "Whither the Nonprofit Wage Differential? Estimates from the 1990 Census", Journal of Labor, 19(1), 136-170.

[24] Handy and Katz (1998), "The wage differential between nonprofit istitutions and corporations: getting more by paying less?", Journal of Comparative Economics, 26, 246-261.

[25] Heyes, A. (2005) "The economics of vocation or -why is a badly paid nurse a good nurse-?", Journal of Health Economics, 24, 561-569.

[26] Keane, M. and A. Merlo, (2010) "Money, Political Ambition, and the Career Decisions of Politicians", American Economic Journal: Microeconomics, 2, 186-215.

[27] Mas-Colell A., M.Whinston and J. Green, (1995) "Microeconomic Theory", Oxford University Press.

[28] Macchaivello R. (2008), "Public sector motivation and development failures", Journal of Development Economics, 86(1), 201-213.

[29] Mattozzi A. and A. Merlo (2008), "Political Careers or Career Politicians?", Journal of Public Economics, 92, 597-608. 
[30] McGuire, T.M. (2008), "Physician Fees and Behaviour: Implication for Structuring a Fee Schedule", in Sloan F., Kasper H. (eds.), Incentives and Choice in Health Care, MIT Press.

[31] Merlo, A., V. Galasso, M. Landi and A. Mattozzi (2009), "The Labor Market of Italian Politicians", PIER Working Paper 09-024, Department of Economics, University of Pennsylvania.

[32] Mervis P.H. and E.J. Hackett (1983), "Work and workforce charateristics in the nonprofit sector", Monthly Labor Review, 106, 3-12.

[33] Messner, M. and M. Polborn (2004) "Paying Politicians", Journal of Public Economics, 88, 24232445.

[34] Naff, K. C. and J. Crum (1999). "Working for America", Review of Public Personnel Administration, $19(4), 5-16$.

[35] Park, S. M. and H. G. Rainey (2008). "Leadership and Public Service Motivation in U.S. Federal Agencies", International Public Management Journal, 11 (1).

[36] Petrovsky, N. (2009), "Does Public Service Motivation Predict Higher Public Service Performance? A Research Synthesis", Unpublished.

[37] Preston A. (1989), "The Nonprofit Worker in a For-Profit World", Journal of Labor Economics, 7, 438-463.

[38] Ritz, A. (2009). "Public Service Motivation and Organizational Performance in Swiss Federal Government", International Review of Administrative Sciences, 75(1), 53-78.

[39] Shields M. A., (2004), "Addressing nurse shortages: What can policy makers learn from the econometric evidence on nurse labour supply?", Economic Journal, 114, F464-F498.

[40] Steijn, B. (2008). "Person-Environment Fit and Public Service Motivation", International Public Management Journal, 11(1), 13-27.

[41] Simoens S., Villeneuve M., Hurst J. (2005), "Tackling Nurse Shortages in OECD Countries", OECD Health Working Papers n. 19.

[42] Weisbrod B.A. (1983), "Nonprofit and Proprietary Sector Behavior: Wage Differential among Lawyers", Journal of Labor Economics, 1, 246-263. 


\section{A Appendix}

\section{A.1 Proof of Observation 1}

Given $w_{0}$, the marginal workers' productivity in the Standard Lemons Model (SLM) is $\hat{\theta}=r^{-1}\left(w_{0}\right)$. For the same wage, the productivity level of marginal workers in the Vocational Lemons Model (VLM) is $\tilde{\theta}=r^{-1}\left(w_{0}+\tilde{\gamma}\right)$. We can compare productivity of the marginal workers in the two models. Since the function $r(\cdot)$ is strictly increasing and $\tilde{\gamma} \geq 0$, it is $r^{-1}\left(w_{0}+\tilde{\gamma}\right) \geq r^{-1}\left(w_{0}\right)$. Thus $\tilde{\theta}=\hat{\theta}$ for $\tilde{\gamma}=0$ and $\tilde{\theta}>\hat{\theta}$ for $\tilde{\gamma}>0$. In other words: for every strictly positive $\tilde{\gamma}$ and $r(\underline{\theta})<w_{0}<r(\bar{\theta})$, in the $V L M$ marginal workers have higher productivity than in the $S L M$.

We now compare average productivity of active workers given $w_{0}$, in the VLM and in the SLM. Let's consider the case where $\bar{\theta}>r^{-1}\left(w_{0}+\bar{\gamma}\right)$ or $\bar{\theta}>\theta_{\text {sup }}$ as in Figure 1, where $\theta_{\text {sup }}$ is the highest productivity level of workers accepting the job for a given salary $w_{0}$. The same reasoning can be applied when $\bar{\theta}<r^{-1}\left(w_{0}+\bar{\gamma}\right)$ or $\bar{\theta}=\theta_{\text {sup }}$.

The probability that workers enter the market at a given salary $w_{0}$ in the $S L M$ is

$$
A=\int_{\underline{\gamma}}^{\bar{\gamma}} \int_{\underline{\theta}}^{r^{-1}\left(w_{0}\right)} f(\theta, \gamma) d \theta d \gamma
$$

whereas the probability that workers enter the market conditional on $w_{0}$ in the $V L M$ is $A+B$, where

$$
B=\int_{\underline{\gamma}}^{\bar{\gamma}} \int_{r^{-1}\left(w_{0}\right)}^{r^{-1}\left(w_{0}+\gamma\right)} f(\theta, \gamma) d \theta d \gamma
$$

In particular, the expected value of $\theta$ given the salary $w_{0}$ in the $S L M$ is

$$
E_{S L M}\left[\theta \mid w_{0}\right]=\frac{\int_{\underline{\gamma}}^{\bar{\gamma}}\left[\int_{\underline{\theta}}^{r^{-1}\left(w_{0}\right)} \theta f(\theta, \gamma) d \theta\right] d \gamma}{A}=\frac{A^{\prime}}{A}
$$

and the expected value of $\theta$ given $w_{0}$ in the $V L M$ is

$$
E_{V L M}\left[\theta \mid w_{0}\right]=\frac{\int_{\underline{\gamma}}^{\bar{\gamma}}\left[\int_{\underline{\theta}}^{r^{-1}\left(w_{0}\right)} \theta f(\theta, \gamma) d \theta\right] d \gamma+\int_{\underline{\gamma}}^{\bar{\gamma}}\left[\int_{r-1}^{r^{-1}\left(w_{0}+\gamma\right)} \theta f(\theta, \gamma) d \theta\right] d \gamma}{A+B}=\frac{A^{\prime}+B^{\prime}}{A+B}
$$

We now prove that $E_{V L M}\left[\theta \mid w_{0}\right] \geq E_{S L M}\left[\theta \mid w_{0}\right] \forall w_{0}$, or

$$
\frac{A^{\prime}+B^{\prime}}{A+B} \geq \frac{A^{\prime}}{A} \text {. }
$$

The previous condition can be rewritten as follows

$$
\frac{B^{\prime}}{B} \geq \frac{A^{\prime}}{A} .
$$

The ratio $\frac{B^{\prime}}{B}$ is the expected value of $\theta$ in the interval $\left(r^{-1}\left(w_{0}\right), r^{-1}\left(w_{0}+\bar{\gamma}\right)\right]$, while $\frac{A^{\prime}}{A}$ is the expected value of $\theta$ in $\left(\underline{\theta}, r^{-1}\left(w_{0}\right)\right]$. The two expected values lie respectively in the two intervals that are not overlapping and then $\frac{B^{\prime}}{B} \in\left(r^{-1}\left(w_{0}\right), r^{-1}\left(w_{0}+\bar{\gamma}\right)\right]$ and $\frac{A^{\prime}}{A} \in\left(\underline{\theta}, r^{-1}\left(w_{0}\right)\right]$. Inequality (5) is thus always valid, for any given $w_{0}$, provided that the probabilities $A$ and $B$ are different from zero. 


\section{A.2 Proof of Remark 1}

(i) Marginal workers in the $S L M$ are $\hat{\theta}: r(\hat{\theta})-w=0$. By totally differentiating the previous equation with respect to $\hat{\theta}$ and $w$ one gets $r^{\prime}(\hat{\theta}) d \theta-d w=0$. Since the function $r(\cdot)$ is strictly increasing, the first claim is obtained. Obviously, the higher the slope of the outside option function $r(\theta)$, the lower the impact of a wage increase on the productivity level of marginal types. (ii) From the proof of Observation 1 , the average productivity of active workers when the wage is $w_{0}$ can be written as follows

$$
E_{S L M}\left[\theta \mid w_{0}\right]=\frac{\int_{\underline{\gamma}}^{\bar{\gamma}}\left[\int_{\underline{\theta}}^{r^{-1}\left(w_{0}\right)} \theta f(\theta, \gamma) d \theta\right] d \gamma}{\int_{\underline{\gamma}}^{\bar{\gamma}} \int_{\underline{\theta}}^{r^{-1}\left(w_{0}\right)} f(\theta, \gamma) d \theta d \gamma}
$$

Since $h(\theta)=\int_{\underline{\gamma}}^{\bar{\gamma}} f(\theta, \gamma) d \gamma$, we can write

$$
E_{S L M}\left[\theta \mid w_{0}\right]=\frac{\int_{\underline{\theta}}^{r^{-1}\left(w_{0}\right)} \theta h(\theta) d \theta}{\int_{\underline{\theta}}^{r^{-1}\left(w_{0}\right)} h(\theta) d \theta} .
$$

We now compute the derivative of $E_{S L M}\left[\theta \mid w_{0}\right]$ with respect to the wage rate and we show that it is always increasing

$$
\frac{\partial}{\partial w_{0}} E_{S L M}\left[\theta \mid w_{0}\right]=\frac{h\left(r^{-1}\left(w_{0}\right)\right) r^{-1}\left(w_{0}\right) \frac{\partial r^{-1}\left(w_{0}\right)}{\partial w_{0}} \int_{\underline{\theta}}^{r^{-1}\left(w_{0}\right)} h(\theta) d \theta-h\left(r^{-1}\left(w_{0}\right)\right) \frac{\partial r^{-1}\left(w_{0}\right)}{\partial w_{0}} \int_{\underline{\theta}}^{r^{-1}\left(w_{0}\right)} \theta h(\theta) d \theta}{\left[\int_{\underline{\theta}}^{r^{-1}\left(w_{0}\right)} h(\theta) d \theta\right]^{2}}
$$

The sign of $\frac{\partial}{\partial w_{0}} E_{S L M}\left[\theta \mid w_{0}\right]$ is the same as the sign of the numerator $(N)$ of the previous expression. $N$ can be rewritten as

$$
N=h\left(r^{-1}\left(w_{0}\right)\right) \frac{\partial r^{-1}\left(w_{0}\right)}{\partial w_{0}}\left[\int_{\underline{\theta}}^{r^{-1}\left(w_{0}\right)}\left[r^{-1}\left(w_{0}\right) h(\theta)-\theta h(\theta)\right] d \theta\right]
$$

Since the function $r(\cdot)$ is increasing and $\theta \in\left[\underline{\theta}, r^{-1}\left(w_{0}\right)\right], N$ is always non-negative.

\section{A.3 Proof of Proposition 1}

Let's consider the proof for the first part of the Proposition. The proof of the second part is equivalent and therefore omitted.

Consider the expected productivity of subjects entering the market for $w=w_{0},{ }^{24} E\left[\theta \mid w_{0}\right]$, that is equal to

$$
E\left[\theta \mid w_{0}\right]=\int_{\underline{\theta}}^{r^{-1}\left(\underline{\gamma}+w_{0}\right)} \int_{\underline{\gamma}}^{\bar{\gamma}} \theta p\left(\theta, \gamma \mid w_{0}\right) d \gamma d \theta+\int_{r^{-1}\left(\underline{\gamma}+w_{0}\right)}^{r^{-1}\left(\gamma+w_{0}\right)} \int_{r(\theta)-w_{0}}^{\bar{\gamma}} \theta p\left(\theta, \gamma \mid w_{0}\right) d \gamma d \theta
$$

\footnotetext{
${ }^{24}$ Without loss of generality, here we consider the case defined both in Figure 1 and in Appendix A.1, where $\bar{\theta}>r^{-1}\left(w_{0}+\bar{\gamma}\right)$ or $\bar{\theta}>\theta_{\text {sup }}$.
} 
where

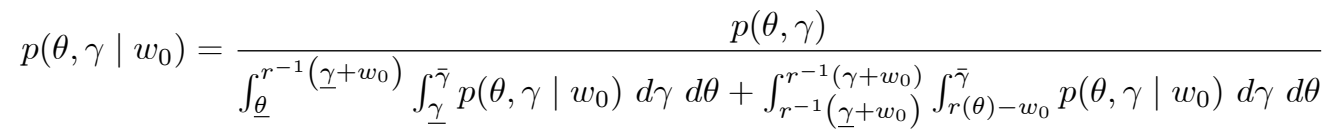

The law of iterated expectations allows us to write

$$
E\left[\theta \mid w_{0}\right]=P\left(A_{1, w_{0}}\right) E\left[\theta \mid A_{1, w_{0}}\right]+P\left(A_{2, w_{0}}\right) E\left[\theta \mid A_{2, w_{0}}\right]
$$

where the two non-overlapping subsets $A_{1, w_{0}}$ and $A_{2, w_{0}}$ described in Definition 2 are such that $A_{1, w_{0}} \cup$ $A_{2, w_{0}}$ is the set of workers entering the market at a given salary $w_{0}$.

Note that, given $w_{0}$, if the condition

$$
E\left[\theta \mid w_{0}\right]=\left(1-P\left(A_{2, w_{0}}\right)\right) E\left[\theta \mid A_{1, w_{0}}\right]+P\left(A_{2, w_{0}}\right) E\left[\theta \mid A_{2, w_{0}}\right] \geq \mu_{\theta}
$$

holds, then the conditional expectation must be decreasing in the wage rate for $w>w_{0}$. In fact, $E_{V L M}[\theta \mid w]$ necessarily converges to $\mu_{\theta}$ for $w$ sufficiently high.

Define $\epsilon_{1}=E\left[\theta \mid A_{1, w_{0}}\right]-\mu_{\theta}$ and $\epsilon_{2}=E\left[\theta \mid A_{2, w_{0}}\right]-\mu_{\theta}$ which are negative and positive numbers respectively. It is obvious that if (6) holds, then necessarily

$$
\left(1-P\left(A_{2, w_{0}}\right)\right) \epsilon_{1}+P\left(A_{2, w_{0}}\right) \epsilon_{2}>0
$$

which is equivalent to inequality (3).

\section{A.4 Proof of Remark 4}

Let us consider the curve of marginal workers $r(\theta)-w_{0}$. The set of active workers conditional on $w_{0}$ can be divided in 4 subsets, $A_{w_{0}}, B_{w_{0}}, C_{1, w_{0}}$ and $C_{2, w_{0}}$, where $A_{w_{0}}$ is such that $E\left(\theta \mid A_{w_{0}}\right)>\mu_{\theta}$ and $E\left(\gamma \mid A_{w_{0}}\right)>\mu_{\gamma}, B_{w_{0}}$ is such that $E\left(\theta \mid B_{w_{0}}\right)<\mu_{\theta}$ and $E\left(\gamma \mid B_{w_{0}}\right)<\mu_{\gamma}, C_{1, w_{0}}$ is such that $E\left(\theta \mid C_{1, w_{0}}\right)<\mu_{\theta}$ and $E\left(\gamma \mid C_{1, w_{0}}\right)>\mu_{\gamma}$, and finally $C_{2, w_{0}}$ is such that $E\left(\theta \mid C_{2, w_{0}}\right)>\mu_{\theta}$ and $E\left(\gamma \mid C_{2, w_{0}}\right)<\mu_{\gamma}$. Then $P\left(A_{w_{0}}\right), P\left(B_{w_{0}}\right), P\left(C_{1, w_{0}}\right)$ and $P\left(C_{2, w_{0}}\right)$ indicate the respective probabilities which add up to one.

Without loss of generality, suppose that $w_{0}$ is sufficiently small that the subset $C_{2, w_{0}}$ is empty. Average productivity for a fixed $w_{0}$ is

$$
E\left[\theta \mid w_{0}\right]=P\left(C_{1, w_{0}}\right) E\left[\theta \mid C_{1, w_{0}}\right]+P\left(B_{w_{0}}\right) E\left[\theta \mid B_{w_{0}}\right]+P\left(A_{w_{0}}\right) E\left[\theta \mid A_{w_{0}}\right]
$$

where, by definition, $E\left[\theta \mid B_{w_{0}}\right]$ and $E\left[\theta \mid C_{1, w_{0}}\right]$ are lower while $E\left[\theta \mid A_{w_{0}}\right]$ is larger than $\mu_{\theta}$.

In the same way, average motivation conditional on $w_{0}$ is

$$
E\left[\gamma \mid w_{0}\right]=P\left(C_{1, w_{0}}\right) E\left[\gamma \mid C_{1, w_{0}}\right]+P\left(B_{w_{0}}\right) E\left[\gamma \mid B_{w_{0}}\right]+P\left(A_{w_{0}}\right) E\left[\gamma \mid A_{w_{0}}\right]
$$


where, by definition, $E\left[\gamma \mid B_{w_{0}}\right]$ is smaller while $E\left[\gamma \mid C_{1, w_{0}}\right]$ and $E\left[\gamma \mid A_{w_{0}}\right]$ are bigger than $\mu_{\gamma}$.

Average productivity and average motivation of active workers converge to $\mu_{\theta}$ and to $\mu_{\gamma}$, respectively, for $w_{0}$ large enough. Thus, two necessary conditions to observe both (monotonic) intuitive effects are

$$
\begin{aligned}
& E\left[\theta \mid w_{0}\right] \leq \mu_{\theta} \forall w_{0} \\
& E\left[\gamma \mid w_{0}\right] \geq \mu_{\gamma} \forall w_{0}
\end{aligned}
$$

implying that $E\left[\theta \mid w_{0}\right]$ converges to $\mu_{\theta}$ from below and $E\left[\gamma \mid w_{0}\right]$ converges to $\mu_{\gamma}$ from above.

Expressions (7) and (8) are jointly compatible with conditions in (9) if and only if the first term in the two expressions is large while the second and the third terms are small; or if $P\left(C_{1, w_{0}}\right)$ is high while $P\left(B_{w_{0}}\right)$ and $P\left(A_{w_{0}}\right)$ are low for every possible level of the wage rate. This requires a negative association between productivity and motivation because it means a large mass in the upper-left part of the set of potential workers together with a small mass in the upper-right and in the bottom-left part of the set of potential workers.

\section{A.5 Simulations}

To show evidence of intuitive and counter-intuitive phenomena, we set a Monte Carlo experiment. In particular, we provide some examples in which counter-intuitive effects are possible both for expected productivity $E[\theta \mid w]$ as well as for expected intrinsic motivation $E[\gamma \mid w]$. Without loss of generality, we set $\underline{\theta}=0, \bar{\theta}=10, \underline{\gamma}=0$ and $\bar{\gamma}=5$. We also assume that the marginal expected values are $E[\theta]=\frac{\theta+\bar{\theta}}{2}$ and

$E[\gamma]=\frac{\gamma+\bar{\gamma}}{2}$. Marginal standard errors have been chosen to keep the truncation rate of our Monte Carlo experiment lower than the $5 \%$. We thus simulated different scenarios, by considering different slopes of the curve of marginal workers and different levels of correlation. To keep the intuition of our experiment as simple as possible, we consider a linear curve of marginal workers, that is, $r(\theta)=\kappa \theta$ and we also refer to the linear dependence between $\theta$ and $\gamma$ described by $\gamma=a+b \theta+\tilde{\varepsilon}$, where $\tilde{\varepsilon}$ is an error term with zero mean and $b=\frac{\operatorname{cov}(\theta, \gamma)}{\operatorname{var}(\theta)}$. Obviously, $b$ is constant and its sign is determined by the sign of $\operatorname{cov}(\theta, \gamma)$.

For each experiment, we simulated a sample of 200,000 subjects with characteristic $\left(\theta_{i}, \gamma_{i}\right)$ from a bivariate Gaussian random variable defined on the joint domain of the two dimensions considered. Expected values of $\gamma$ and $\theta$ given the wage level $w$ are computed through Monte Carlo integration.

We refer to Remark 2 and first consider the case where the slope of the line of marginal workers is lower than the regression slope, by setting $b=1.7$ and $\kappa=1.5$. Panel A in Figure 3 shows that $E[\theta \mid w]$ as well as $E[\gamma \mid w]$ are decreasing. Thus, we observe a counter-intuitive behavior for the expected $\theta$.

In the second scenario, we keep the slope of the line of marginal workers $\kappa=1.5$ unchanged, while we decrease the slope of the regression line so that $b=0.6$. In this case, the line of marginal workers is thus steeper than the linear relation. Panel B in Figure 3 shows an increasing expected productivity and an increasing expected vocation. Therefore, in this scenario, we observe a counter-intuitive behavior for the 
expected $\gamma$.

If we take the very same experiment and uniquely switch the sign of the covariance (from positive to negative), both intuitive effects occur. In particular, we assume $b=-0.6$ and $\kappa=1.5$. In Panel C of Figure 3 we find evidence for an increasing average productivity and a decreasing average vocation of active workers.

Finally, we consider the same slope for the regression line as in case $\mathrm{B}$, namely $b=0.6$, together with a lower coefficient, $\kappa=0.4$. Panel $\mathrm{D}$ in Figure 3 shows a decreasing average productivity and a decreasing vocational level as shown in case A above. Again, this result is counter-intuitive with respect to the $\theta$ dimension.

In Section 4, we have already described the link between Case A of the simulations and Proposition 1 using the plot of the 200,000 potential workers (Figure 4). Here we consider Case B. In Figure 5, we observe the whole population inside the set of potential workers, together with the average values of $\theta$ and $\gamma$, the regression line and the line of marginal workers defined by a wage rate equal to 3.5. The line of marginal workers splits the set of active workers into the two subsets $B_{1, w_{0}=3.5}$ and $B_{2, w_{0}=3.5}$. As Figure 5 shows, Condition (4) is verified for $w_{0}=3.5, P\left(B_{\left.1, w_{0}=3.5\right)}\right)$ being clearly larger than $\left(1-P\left(B_{1, w_{0}=3.5}\right)\right)$. Moreover, observing workers who are out of the vocational market for $w_{0}=3.5$, it is evident that, when the wage rate increases, better workers will enter the market (workers with higher productivity and higher motivation with respect to the average characteristics of those already active for $w_{0}=3.5$ ). Finally, note that Condition (3) is not verified for $w_{0}=3.5, P\left(A_{2, w_{0}=3.5}\right)$ being close to zero and so clearly lower than $\left(1-P\left(A_{2, w_{0}=3.5}\right)\right)$.

Cases $\mathrm{C}$ and $\mathrm{B}$ of the simulations can be interpreted following the very same reasoning.

Insert Figure 5 about here

\section{A.6 Dependences between productivity and vocation in real data}

In Subsection 4.1, we showed that a positive dependence between productivity and motivation given the wage is a necessary condition for counter-intuitive results to occur.

To see whether this condition is statistically relevant, we use data from the Survey ICSI 2007 (Indagine Cooperative Sociali Italiane, or the Survey on Italian Social Cooperatives). As we already mentioned in the main text, we do not interpret the association between motivation and productivity as casual, but simply as documenting their statistical connection.

Note that, by analyzing workers already in the vocation-based sector (employees in the cooperatives), we are just verifying the sign of the conditional covariance defined by the wage rate observed in the sector when the survey was performed, namely $\operatorname{cov}\left(\theta, \gamma \mid w_{0}\right)$. 
The survey consists of 4,134 interviews with employees and 388 interviews with managers, from 441 Italian cooperatives in the non-profit sector. It is worth noting that the non-profit sector can be reasonably considered as a vocation-based one. The survey comprises a large set of questions, ranging from socio-demographic controls (i.e. age, gender, education, etc.) to economic variables (i.e. wage), job characteristics (i.e. tasks, working hours, overtime) and job satisfaction with respect to a number of possible domains (with colleagues, wage, type of job).

In particular, the ICSI survey includes the question "How do you define your relationship with the cooperative?", the answer to which can be considered as a proxy for workers' motivation. In fact, workers were asked to give their degree of consensus (on a 1 to 7 scale) to the following possible answers to the previous question:

1. a mere contractual relationship where a job is exchanged for pay.

2. a contribution which helps the cooperative to reach its goal.

3. a mix between professional growth and personal development.

4. a set of relationships which goes beyond a mere contractual relationship.

5. a social commitment shared by the respondent and the cooperative.

The previous statements are indicated in our empirical analysis, respectively, as Vocation_1, Vocation_2, Vocation_3, Vocation_4, Vocation_5, which are qualitative variables.

As a proxy for the productivity, we consider bonuses and cash prizes that workers received as an extra earning with respect to their monthly wage. Furthermore, the monetary value of monthly benefits possibly received by employees (for instance free phone calls) is added to bonuses and cash prizes. Of course, while all workers provided an answer to the questions concerning intrinsic motivation, only a fraction of them declared that they received monthly bonuses and cash prizes or monthly benefits, or both. In particular, the percentage of workers that received benefits or bonuses is about $28 \%$ of the total workers. For this reason, in order to measure the relationship between motivation and productivity we consider a Tobit model, in which "monthly bonuses and cash prizes with benefits" (bonus_benefit) is the dependent variable. We consider the following specifications

$$
\text { bonus_benefit }=\left\{\begin{array}{ll}
\beta^{\prime} X+\epsilon & \text { if bonus_benefit }>0 \\
0 & \text { otherwise. }
\end{array},\right.
$$

in which $\epsilon$ is a Gaussian error term with zero mean, $X$ is the vector of regressors, and the linear part of 
the model is defined as

$$
\begin{aligned}
\beta^{\prime} X= & \beta_{0}+\beta_{1} \text { sex }+\beta_{2} \text { italian }+\beta_{3} \text { permanent }+\beta_{4} \text { status }+\beta_{5} \text { type }+ \\
& \beta_{6} \text { age }+\beta_{7} \text { no_school }+\beta_{8} \text { primary_school }+\beta_{9} \text { secondary_school }+ \\
& \beta_{10} \text { professional_school }+\beta_{11} \text { other_school }+\beta_{12} \text { high_school }+ \\
& \beta_{13} \text { univ_degree }+\beta_{14} \text { south }+\beta_{15} \text { north } / \text { west }+\beta_{16} \text { north } / \text { east }+ \\
& \beta_{17} \text { tenure }+\beta_{18} \text { full_time }+\beta_{19} \text { worked_hours }+\delta_{i} \text { vocation_i. }
\end{aligned}
$$

In particular, we evaluate 5 different models, corresponding to the five vocation statements, i.e. vocation_1,...,vocation_5.

We also consider a number of dummy variables as control variates. In particular, permanent means that the worker has a permanent position, status specifies whether the worker is also a member of the cooperative or not, type refers to the type of the cooperative ${ }^{25}$, south, north/west, north/east and center refer to the geographical location of the cooperative ${ }^{26}$, tenure indicates the years spent in the cooperative by the worker, full_time indicates full time job, and finally worked_hours states the hours worked per month in the cooperative. We also considered the nationality (italian) and the schooling level (no_school, primary_school, secondary_school, professional_school, high_school,univ_degree, univ_laurea and other_school $)^{27}$.

Our empirical findings are illustrated in Table 1. In the specification, we find that all the vocational coefficients except the first one (which, as expected, is negative) have a positive and significant impact on productivity; in particular, consensus to Vocation_1 and Vocation_2 are significant at the 1\% level, while consensus to Vocation_3, Vocation_4, and Vocation_5 are significant at 5\%. These findings provide evidence of a positive dependence between vocation and productivity for a given level of wage, at least when productivity is measured by "monthly bonuses and cash prizes with benefits". ${ }^{28}$

Our empirical analysis suggests that the hypothesis of positive conditional correlation between voca-

\footnotetext{
${ }^{25}$ Two types of cooperatives are considered: "cooperatives A" manage health and education services, "cooperatives B" have the goal of inclusion of disadvantaged workers (disabled, ex-prisoners, ex-drug addicts...) in industry, agriculture and trade.

${ }^{26}$ Note that center has been omitted to avoid collinearity.

${ }^{27}$ In particular we indicate by univ_degree a 3 year university degree, whereas by univ_laurea we refer to a $4 / 5$ year degree.

${ }^{28} \mathrm{~A}$ possible objection to the previous empirical strategy is that there could be a firm-specific effect in the cooperative sector, meaning that the majority of the cooperatives give almost all their workers some bonuses and/or benefits. However, as shown in Figure 6, the proportion of cooperatives providing bonuses and/or benefits to a given percentage of workers is substantially uniform over the sample. From the figure, it is clear that only a few cooperatives provide extra wages to all the workers, while many cooperatives provide extras only to a low fraction of people.
} 
tion and productivity is reasonable.

\section{Insert Table 1 here \\ Insert Figure 6 here}

An interesting caveat of the empirical analysis is that we cannot use the workers' wage rate as a proxy for productivity, even if workers' monthly wage is available in the data (some small differences in the workers' wage rate exist, suggesting that the wage rate is not exactly uniform in this vocation-based sector). In fact, by considering the wage rate as a proxy for productivity we implicitly assume that the wage rate is always increasing in productivity, which obviously implies that productivity is always increasing in the wage. However, results from the theoretical model show that average productivity of active workers can be decreasing in the wage rate. Thus, if we used the wage rate as a proxy for productivity as in the standard empirical literature on labor, the empirical analysis would not be coherent with our theoretical results. ${ }^{29}$

\footnotetext{
${ }^{29}$ Such an empirical strategy is precisely used in Becchetti et al. (2009) who use the same ICSI 2007 survey and find clear evidence of positive correlation between intrinsic motivation and wage. In particular, in their empirical specification based on the "monthly wage" as dependent variable, the authors found that consensus to the last four vocational statements has a positive and significant effect on wages.
} 


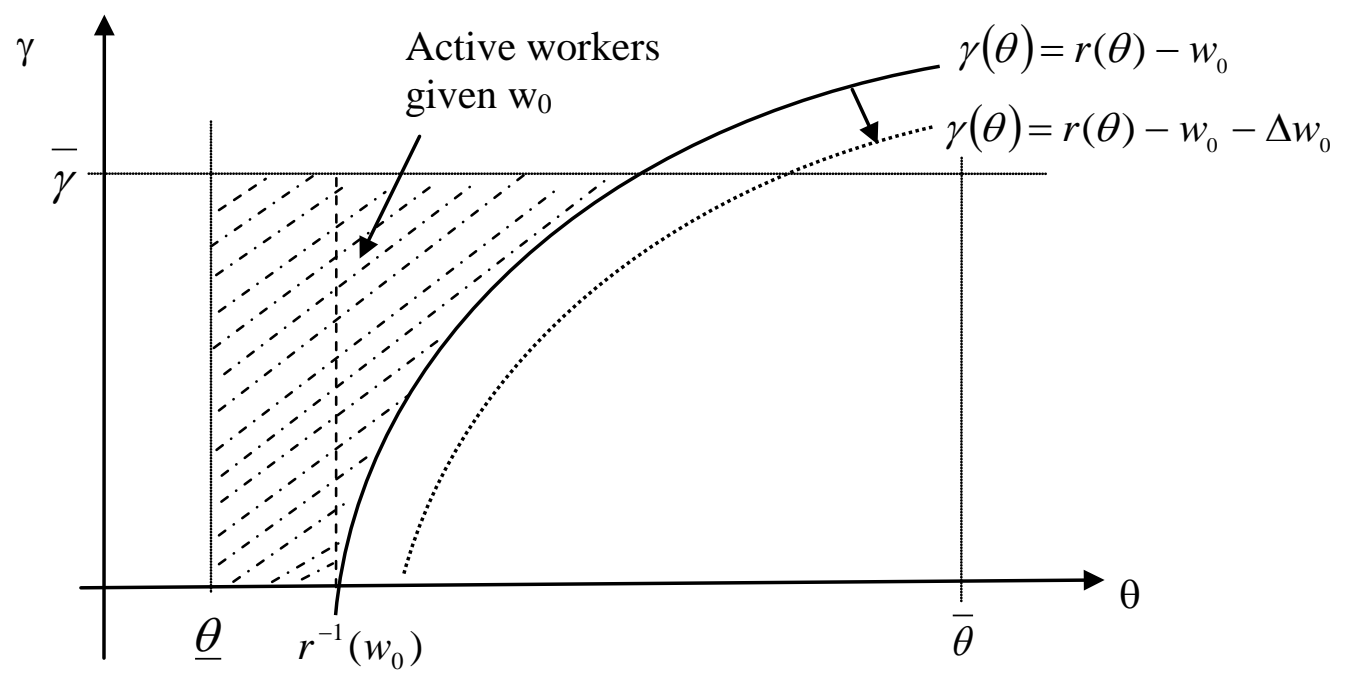

Figure 1: the set of potential workers and the curve defining marginal workers given salary $\mathrm{w}_{0}$.

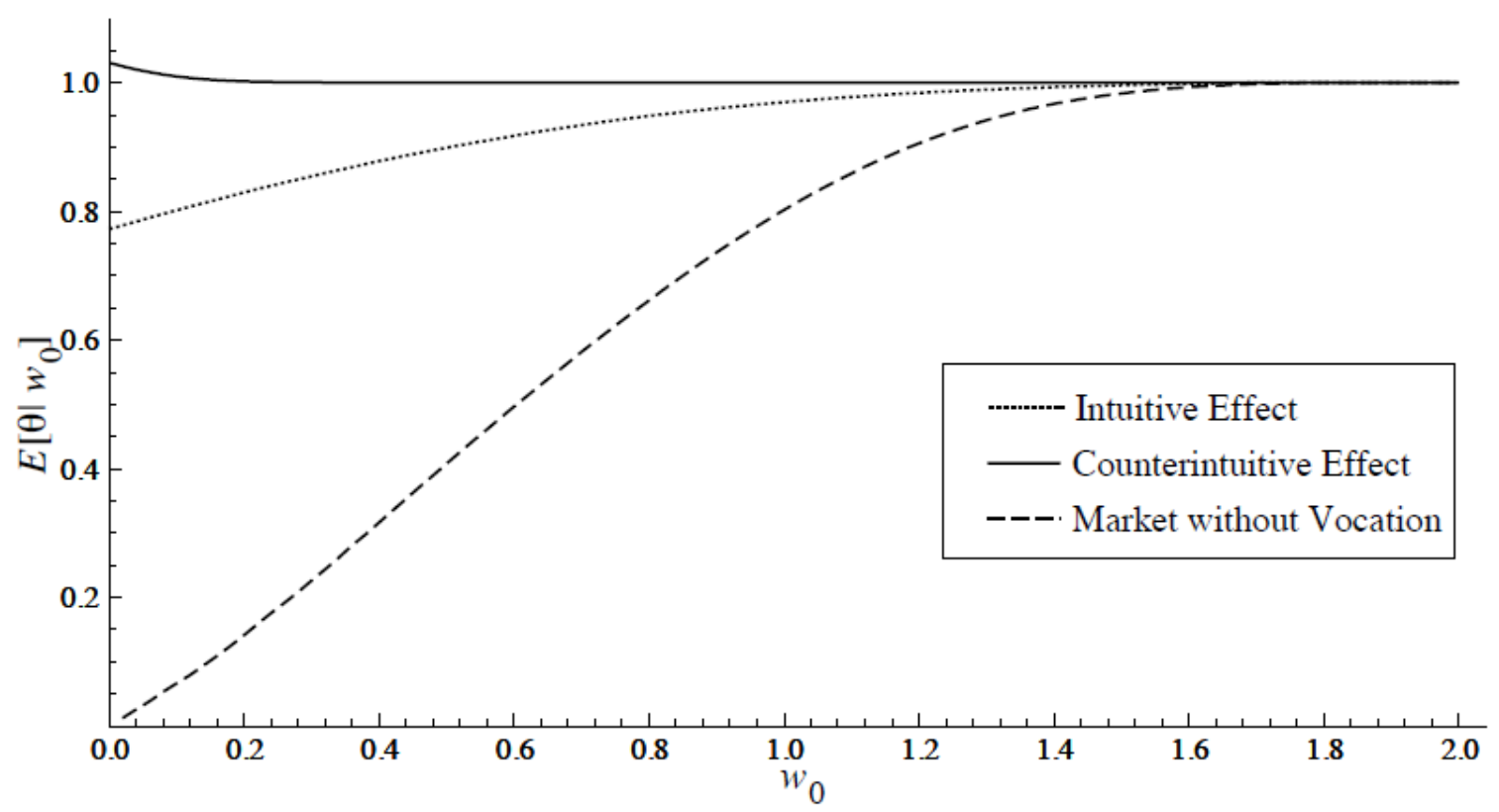

Figure 2. In the standard market, expected productivity given the wage is monotonically increasing with the wage rate. In the vocational market, instead, counterintuitive effects can occur. In the figure, a case with average productivity monotonically decreasing and a case with average productivity monotonically increasing with the wage rate are shown. 


\section{Case A: $\mathrm{k}=1.5, \mathrm{~b}=1.7$}
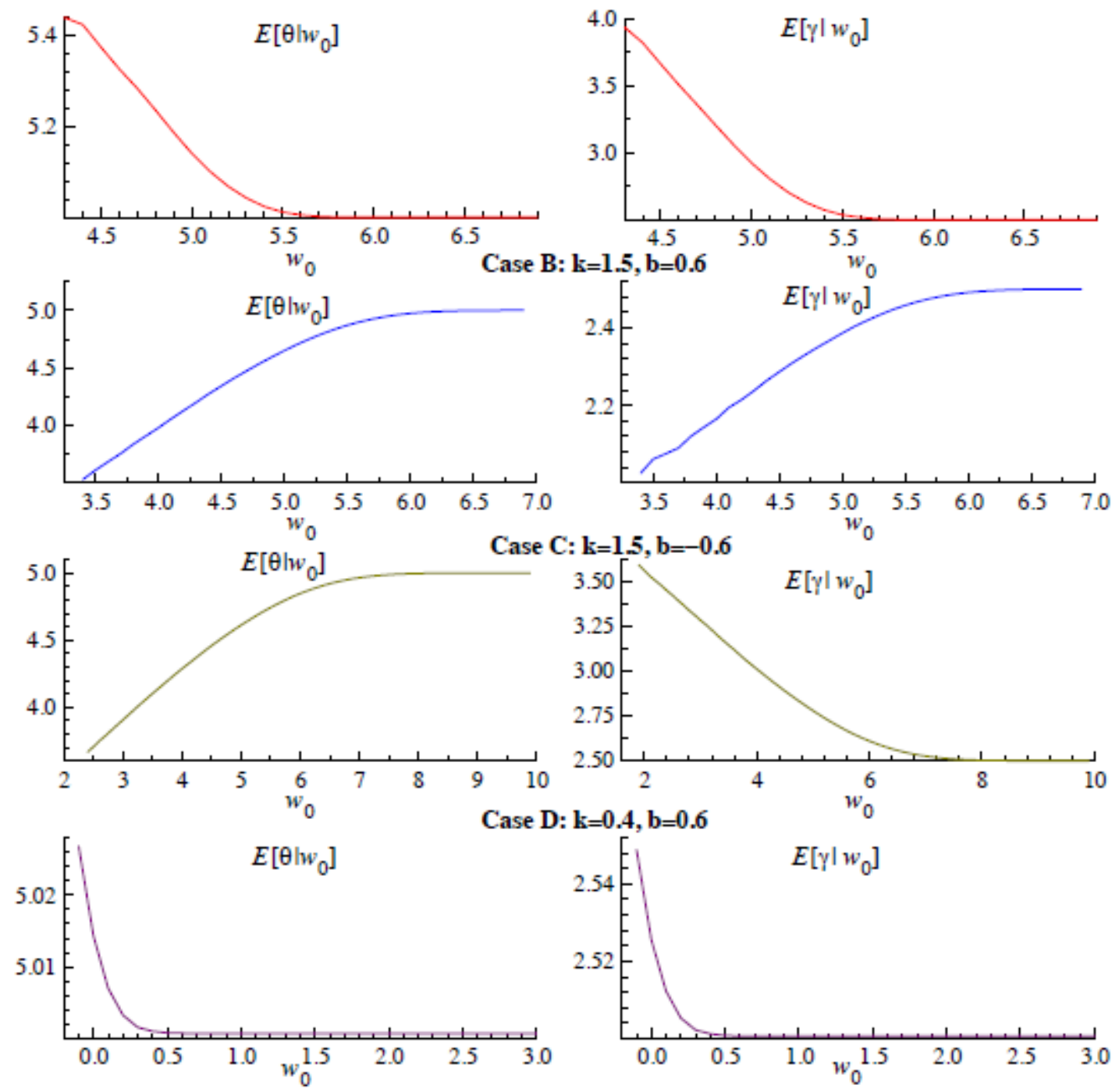

Figure 3: Simulations. Case C shows intuitive effects. Cases A, B and D depict counterintuitive effects. Cases A and D present the counterintuitive (and monotonic) effects as for average productivity of active workers, Case B as for average vocation. 


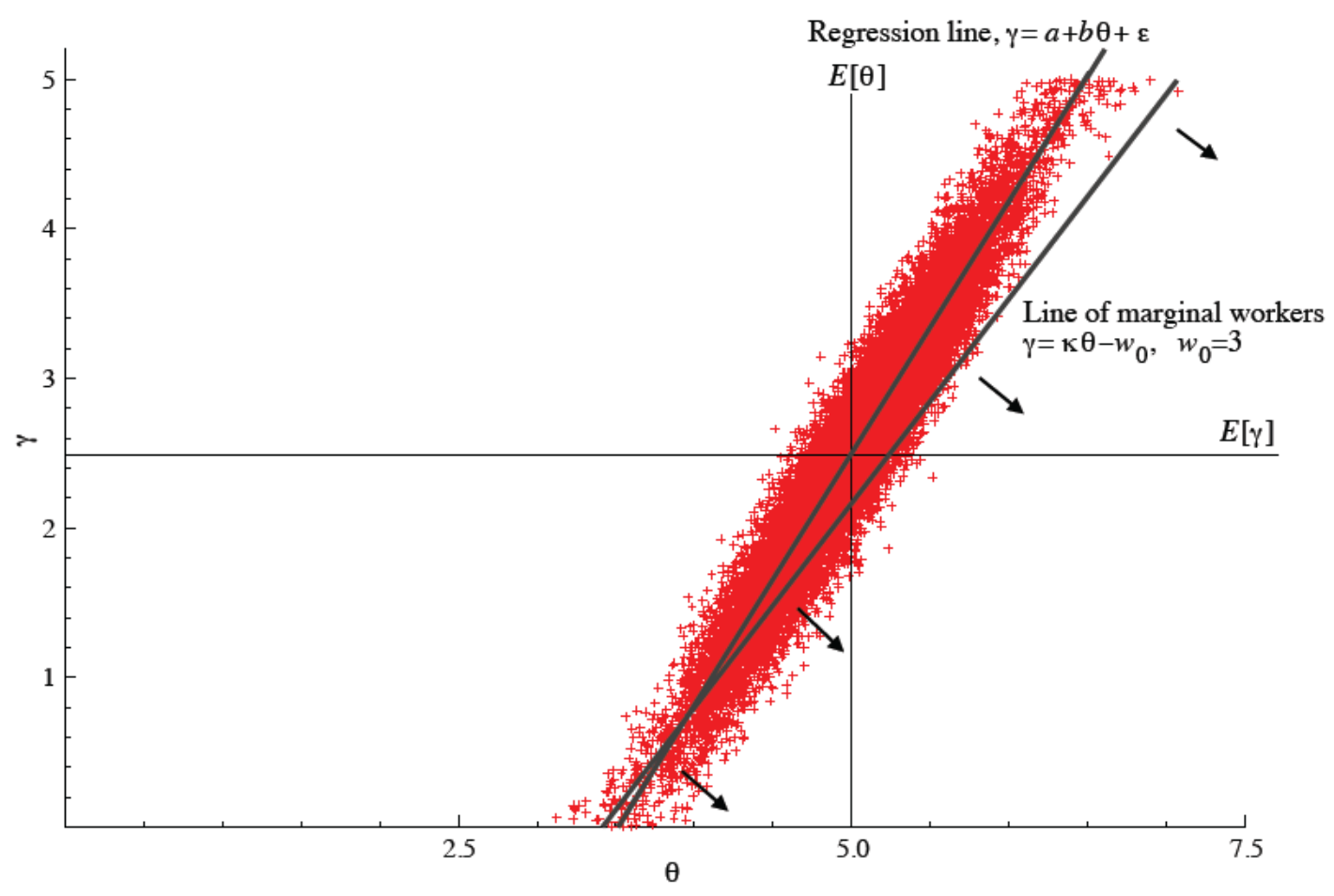

Figure 4: Explanation of case A of the simulations.

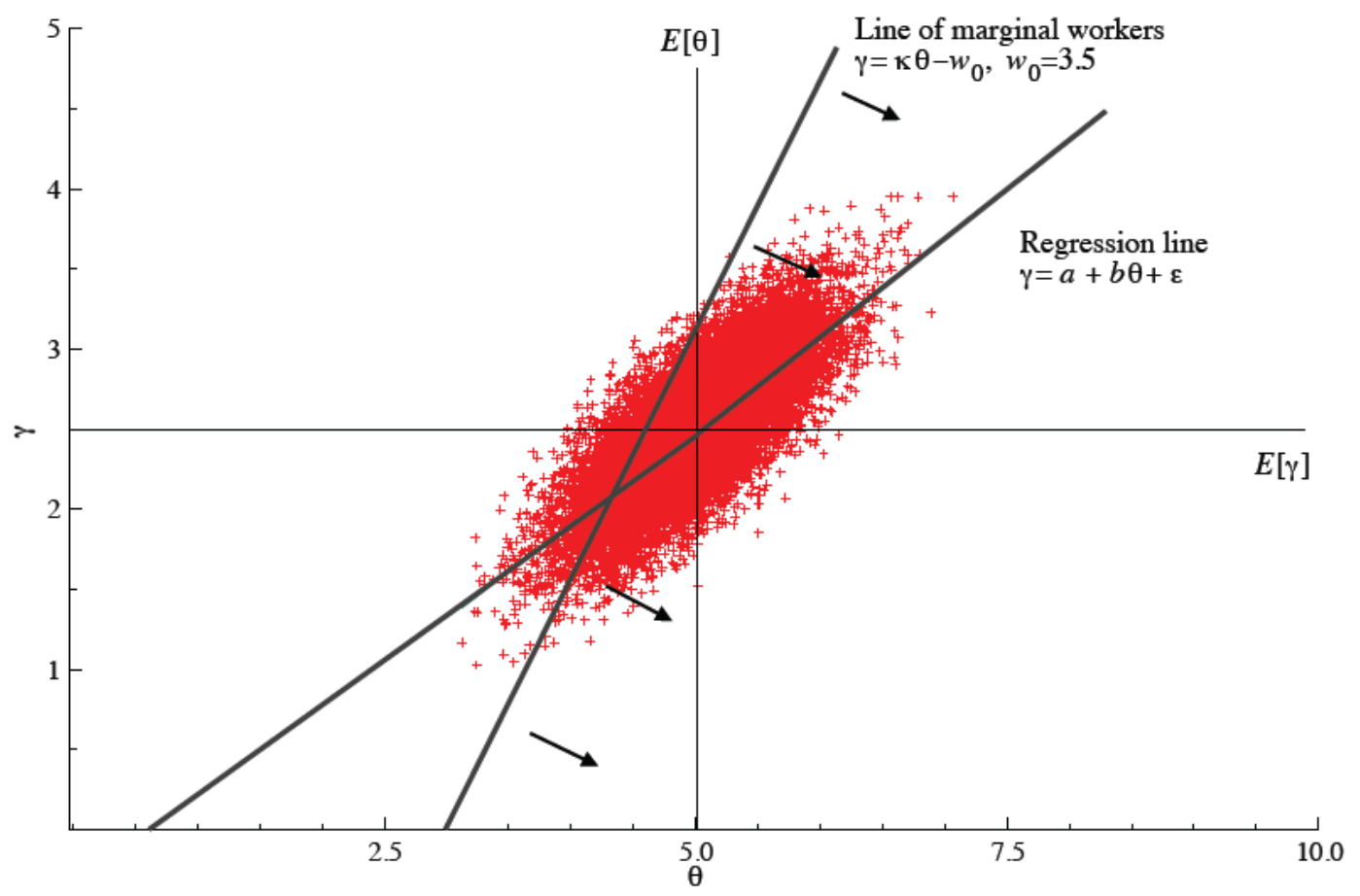

Figure 5: Explanation of case B of the simulations. 
Number of cooperatives for each category.

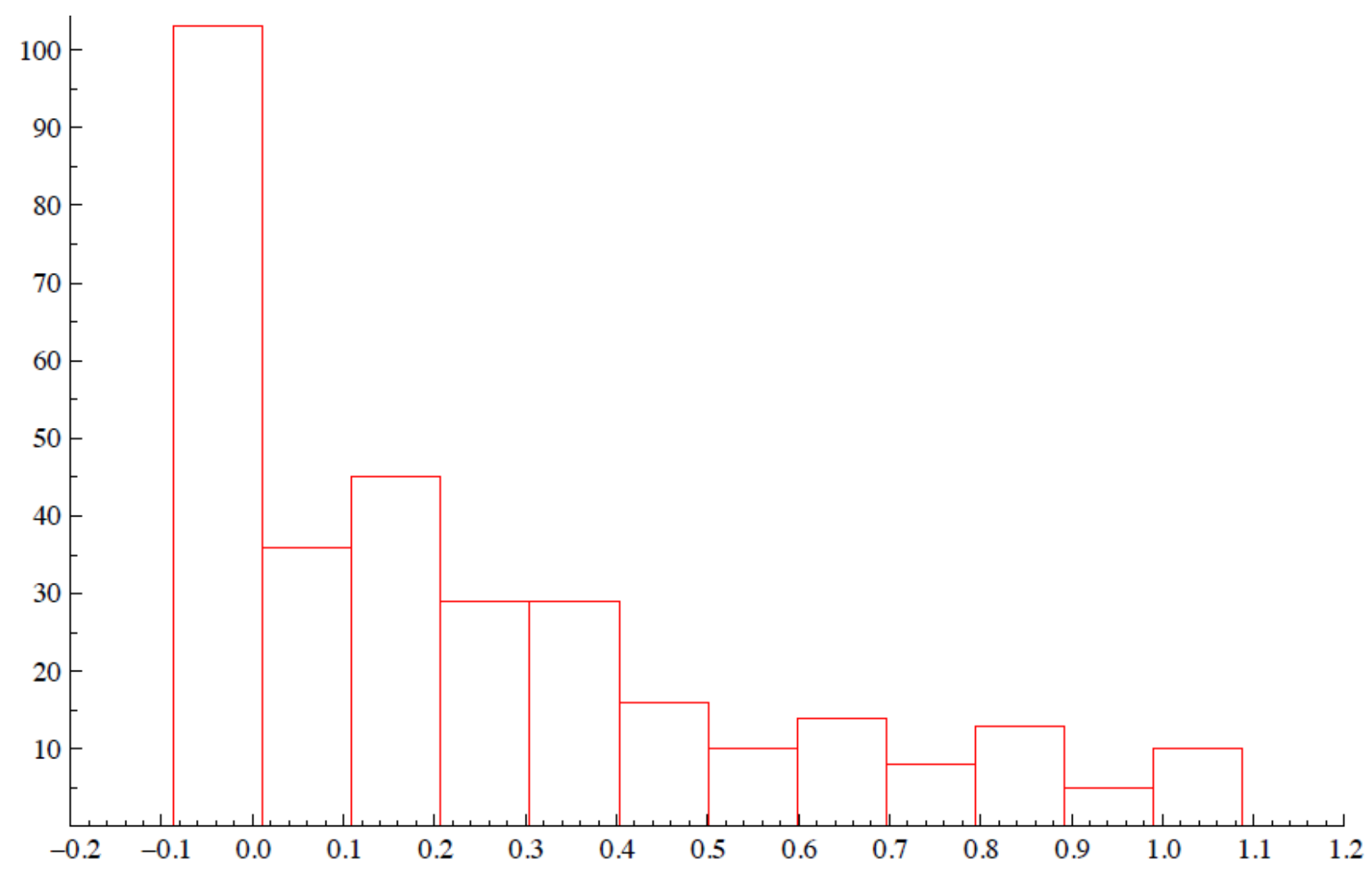

Figure 6: Histogram of frequencies for cooperatives that provide bonus/benefits to their workers. In particular, in the $\mathrm{x}$-axis we report the percentage of workers for each cooperative receiving bonuses and/or benefits in the sample (Survey ICSI 2007). 


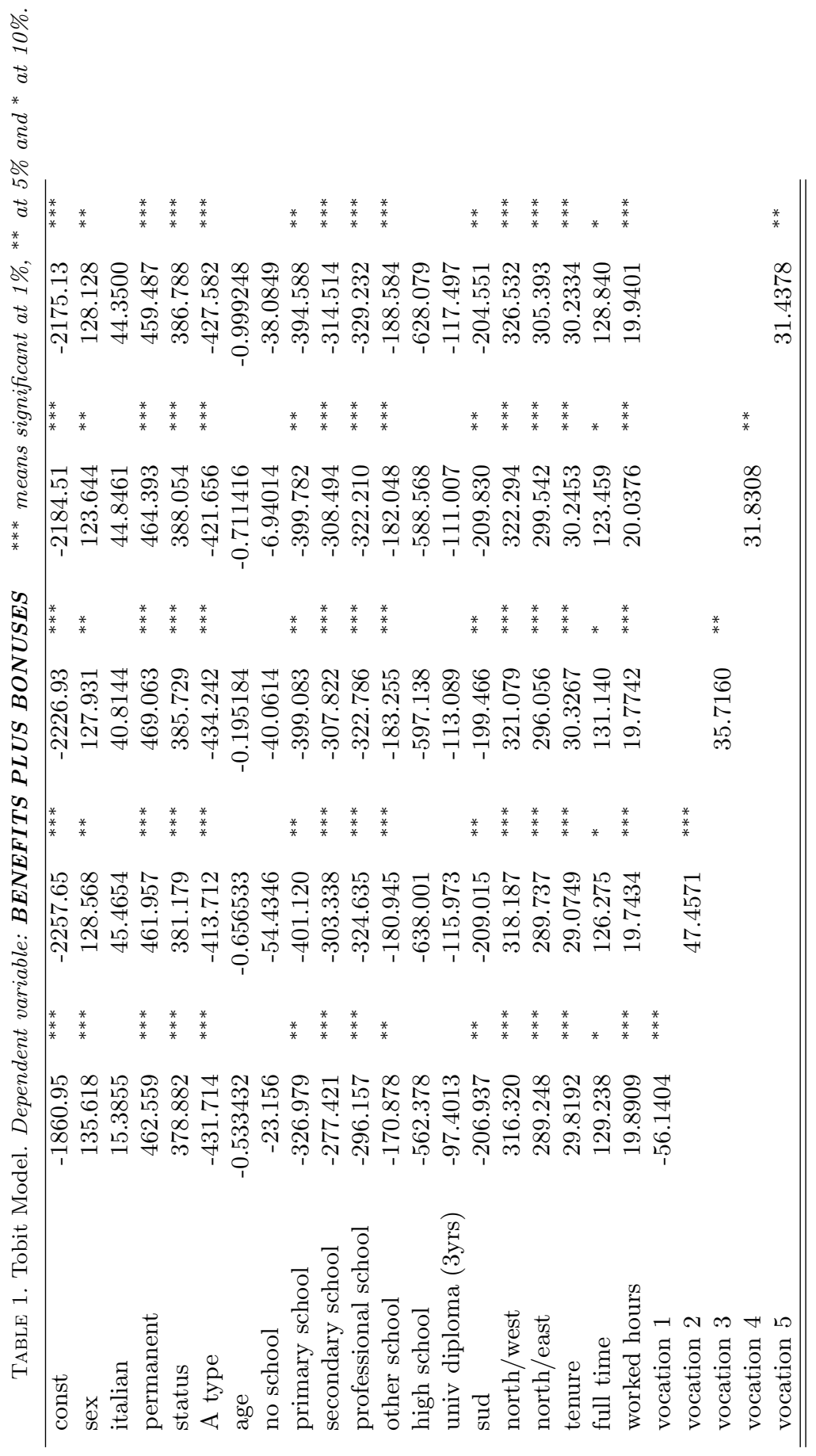




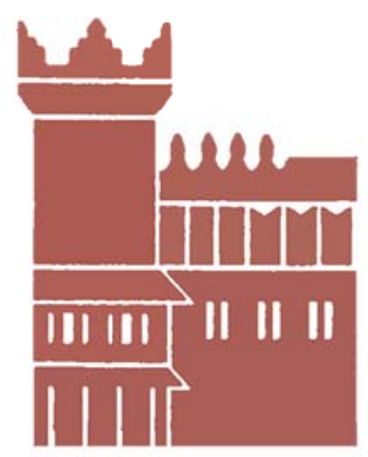

Alma Mater Studiorum - Università di Bologna DEPARTMENT OF ECONOMICS

Strada Maggiore 45

40125 Bologna - Italy

Tel. +39051 2092604

Fax +390512092664

http://www.dse.unibo.it 